\title{
School Closures During the COVID-19 Pandemic: Psychosocial Outcomes in Children - a Systematic Review
}

\author{
Juliane Lehmann, Viola Lechner and Herbert Scheithauer*
}

\author{
Freie Universität Berlin
}

\begin{abstract}
With implemented school closures, the global crisis of COVID-19 has caused drastic changes in the dynamics and routines of children and their families. The rapid transition to homeschooling and social distancing measures have been particularly challenging for schoolchildren and their parents. In the adverse situation of COVID-19, children are more vulnerable to contextual factors such as familial risks, leading to unfavorable outcomes in children's mental health, their emotional and psychosocial development. The present study aimed to synthesize available literature on psychosocial outcomes in schoolchildren (ages 6-13 years) who were exposed to family-related stressors during mandatory school closures. A systematic review was carried out, following the PRISMA guideline. A total of 419 records were retrieved from electronic databases, journals, and reference lists of primary studies and reviews. Studies were analyzed by the interrelation of negative child outcomes and parent-related variables during the period of school closure. Ten studies were included in this review. Studies varied in quality, in the combination of psychosocial factors, and child outcomes. Identified psychosocial variables impacting children included parental mental health, parental stress, parent-child interaction, and parenting stress. Identified negative outcomes in children encompassed emotional problems, behavioral problems, hyperactivity, anxiety and depression. Overall, results highlighted the link between children's psychological response and parent-related variables during school closures. Results show that pandemic-related school closures had a considerable effect on children. However, findings cannot be interpreted conclusive as studies measured other factors, that contributed to a child's psychological status quo.
\end{abstract}

Keywords

School closures, COVID-19, children, psychosocial outcomes, parent-child relationship

The global outbreak of SARS-CoV-2 pandemic in March 2020 had negative consequences in many ways. As part of the measures in many countries, widespread school closures were prompted to control transmission dynamics by reducing social contacts within educational facilities; which is known to slow down community spreading. In the beginning of the

\footnotetext{
*Address for correspondence

Dr. Herbert Scheithauer, Department of Education and Psychology, Freie Universität Berlin, Berlin, Germany. E-mail: herbert.scheithauer@fu-berlin.de
}

pandemic school closures as an effective means to slow community spreading was entirely based on influenza research (Jackson et al., 2016); controversially discussed within the scientific community, as the role of community transmission of SARS Cov2 was less clear at the time (Lewis et al., 2021; Viner et al., 2020). Data on COVID-19 infection rates revealed that children and adolescents are far less likely to become ill compared to adults. Some research even suggests younger children are less likely to infect other people (Brandal et al., 2021; 
Cavallo et al., 2020; Ludvigsson, 2020; Macartney et al., 2020). However, recent research has revealed that high community transmission rates correlate with transmission rates within school settings, if prevention strategies (e. g. vaccinations) are not implemented (Ismail et al., 2021; Mossong et al., 2021). However, school closures take its toll psychosocially and at the same time distance- learning weighs hard on children: children miss out on social interaction with peers and teachers, and are deprived of essential academic and social learning, which determines trajectories of development and growth. At the height of the pandemic's first wave nearly 1.47 billion students in 170 countries were affected by school closures, among which approximately 463 million students had no access to remote learning due to lacking internet access at home (UNESCO, 2020). According to a report by UNICEF, schools closed their doors for an average of 95 instruction days between March 11, 2020 and February 2, 2021 (UNICEF, 2021). After the one-year mark of the COVID-19 pandemic, for many countries, in-person instruction remains disrupted; some schools never reopened. Students, parents and educators are left with uncertainty. Ultimately, children face a situation they have to unwillingly cope with, impacting their health, well-being and education long-term.

\section{Unintended Consequences of School Closures}

The school environment provides by far more than mere education. Children rely on school as a "safe haven" nurturing them with safety, social activities, healthy meals, a place to establish positive relationships with peers and educators, and as a resource to strengthen competencies. In school children find opportunities for contribution and participation. While in quarantine, children struggle with emotional, social, and cognitive impairments due to psychosocial risk factors overweighing protective factors, which are represented by the social system "school". The ongoing social deprivation and disruption from education, peer and teacher relations emphasizes the importance of school as an optimal environment in which children can flourish and attain competencies in order to master the challenges of life.

There is a growing body of research stating detrimental effects of school closures on children's mental health and development (Araújo et al., 2021; Lee, 2020; Xie et al., 2020). Due to social isolation children experienced increased levels of loneliness by lacking contact with peers and teachers, which is normally catered by the school's environment. For instance, in a rapid systematic review by Loades et al. (2020), a link between loneliness and depression among children and adolescents was found. Overall, the longer the duration of loneliness, the more the prediction for future mental health problems (Loades et al., 2020). Generally, mental health problems in children and adolescents show a poor prognosis and can result in conduct disorders, depressive disorders, and anxiety disorders (Ihle \& Esser, 2002), which potentially threatens the academic (McLeod \& Kaiser, 2004; Miller-Lewis et al., 2014), social and emotional functioning of a child (Thomson et al., 2019). Another important chief concern is the psychosocial impact of the domestic environment and the familial system children find themselves in during lockdown, while in-person instruction remains disrupted. While schools are closed, certain risk factors existent in a family environment may moderate psychosocial outcomes in children and influence their mental health as well as their development. In times of COVID-19, families are additionally burdened with drastic lifestyle changes, ranging from stressors such as job loss, reduced income, to fulltime childcare and home schooling, which decreases the level of family well-being and life-satisfaction among parents (Huebener et al., 2021). School closures also contributed to a greater level of family stress due to the balancing of employment demands such as working hours and home schooling. Female caregivers, especially, with school aged children bear the responsibility of childcare, experience the brunt of reduced working hours or job losses during the pandemic (Collins et al., 2021). As a consequence, these temporary stressors cascade down to children, which may show reciprocal and unintended effects in behavior, well-being, and mental health. Wickens et al. (2021) reported depressive symptoms to occur more likely in households with 4+ persons as well as in households with children age six to 12 years during lockdown. Clearly, the COVID-19 pandemic outlines the contextual risk families have to face, which impedes family functioning, adding a newfound struggle to familylife. Furthermore, certain environmental risk factors are pre-existent, highlighting inalterable parameters which shape the upbringing of a child, and at the same time shed light on a child's socio-emotional development. Key findings from several studies suggested an association between poor mental health in a child and psychosocial risk factors, such as parental psychopathology (Hammen et al., 1990; Rutter \& 
Quinton, 1984), interparental conflicts (van Eldik et al., 2020), low socio-economic status (SES) (Bradley \& Corwyn, 2002), parental alcoholism (Raitasalo et al., 2019), poor housing quality (Rollings et al., 2017), or domestic violence (Holt et al., 2008) - to name a few of the most studied risk factors. Under COVID-19, children might be at the mercy of various risk factors with no social support outside of their familial microsystem. To sum it up, pandemic related school closures may exponentiate childhood adversity both by the loss of an essential social framework and the climax of familial and social difficulties while being in remote learning.

\section{Situation Prior to and During the COVID-19 Pandemic: Results From Longitudinal Studies}

Studies that examined the same children before and after or during the COVID-19 pandemic provide insight into the impact of the pandemic on children's mental health. On the basis of the representative BELLA study, mental health issues related to psychosocial risk factors were found in German children prior to the pandemic (Otto et al., 2020; RavensSieberer \& Kurth, 2008; Ravens-Sieberer et al., 2015). According to the longitudinal data ( $n=1.556$ families) collected during the fourth BELLA followup study (2017), the prevalence of noticeable mental health issues in children was $9.9 \%$ (Otto et al., 2020). Along with biological risk factors, psychosocial risk factors account for a great proportion in mental health in children. For instance, Wille et al. (2008) reported twice as many children $(26 \%)$ with mental health issues came from families with a low socio-economic status (SES) compared to children from households with high SES (10\%). Children with psychopathological burdened parents were more vulnerable towards mental health problems (38\%) vs. children with parents with no psychopathological burden (13\%) (Wille et al., 2008). The COVID-19 pandemic clearly enhances the severity of risk factors and the percentage of mental health issues in children. The representative longitudinal COPSY study conducted in Germany during the two waves of the pandemic in May and June $2020(n=1.586$ families) (Ravens-Sieberer et al., 2021b) and in December 2020 and January $2021(n=1.625)$ (Ravens-Sieberer et al., 2021a) measured mental health and risk factors for mental health problems in children (age 7-17) during the pandemic. Data revealed $17.8 \%$ of children in the first wave and $20.3 \%$ of children in the second wave suffered from noticeable mental health problems (Ravens-Sieberer et al., 2021a). Specifically, children from families with a low SES, scarce living spaces, or from a migrant background were more severely affected by the burden of the pandemic in comparison to peers in low-risk environments (42.5\% vs. $26.7 \%$ ) (Ravens-Sieberer et al., 2021b). Parents of at risk reported more emotional symptoms, poorer mental health and conduct problems in their children. This illustrates existing disparities between individuals who are exposed to deprived environments and optimal familial environments. The mentioned findings before and during the pandemic are in line with results of non-representative studies (Gassman-Pines et al., 2020; Jiao et al., 2020; Ormel et al., 2012; Posserud \& Lundervold, 2013).

\section{The Interrelation of Development and Mental Health Within the School Setting}

A positive school climate, a social support system by educators and peers promotes mental health in children and adolescents at risk (Plass et al., 2016). A good mental health status is intertwined with the successful accomplishment of developmentally appropriate tasks via developmental competencies. School provides a social context in which academic achievements, following rules for appropriate behavior and the development of positive peer relations are established (Masten \& Coatsworth, 1995) as well as resilience - the ability to cope with adversity (Masten et al., 2005). Pandemic related school closures may invoke failures in developmental competencies and contribute to negative psychosocial, also emotional outcomes and psychopathology. In his Developmental Tasks Theory (Havighurst, 1956), Havighurst posited a successful accomplishment of developmental tasks aimed to prepare "subsequent levels of maturity and provides mental and socio-emotional tools to face life's challenges" (Bowler \& Weinraub, 2018, p. 596). According to this theory, school plays a key role during childhood. At school, children acquire social, emotional, and other skills (e.g. computational skills) via developmental tasks. The concept of developmental tasks approaches socio-cultural standards individuals should reach to guarantee social functioning. The positive impact of the school environment on children's mental health, as well as their psychosocial and emotional development, is of importance. As a protective factor, the microsystem "school" can 
buffer risk factors threatening positive psychosocial outcomes and thus mental health.

\section{Aims of the Present Systematic Review}

According to current data and knowledge, no review has systematically collected quantitative data regarding pandemic-related school closures and psychosocial outcomes in children contingent on potential psychosocial risk factors; which may harm children's mental health and their emotional and psychosocial development. The international prospective register of systematic reviews "Prospero", has been checked for previous and ongoing systematic reviews which probe the interplay of pandemic- related school closures and psychosocial outcomes in children. Zhang et al. (2020) exclude impacts of pandemicrelated school closures and instead take a wider look at mental health outcomes in children amidst COVID19 and past pandemics. In another ongoing systematic review Packer et al. (2020) synthesize data of the impact of school closures on (1) physical and mental health in children and (2) differentiated between longterm and short-term effects. Apart from the Prospero research, a previous systematic review by Berger et al. (2021) was found on Pubmed. According to this systematic review, risk factors such parental mental health concerns were taken into account, resulting negatively in children's mental health. For instance, if parents in quarantine showed clinical features of post-traumatic stress disorder (PTSD), children most likely developed PTSD symptoms as well. However, Berger et al. (2021) waive COVID-19 related school closures and refer to various infection outbreaks as SARS, COVID-19, Middle East Respiratory Syndrome (MERS) and influenza.

Therefore, the present study aims to systematically review quantitative observational studies (i) to present an overview of the interrelation between pandemic-related school closures and psychosocial outcomes in children, (ii) to examine whether the empirical evidence supports or contradicts the theoretical hypothesis.

\section{Method}

\section{Inclusion and Exclusion Criteria}

The PRISMA protocol (http://prisma-statement.org/) was followed in conducting this review. Eligible stud- ies met inclusion criteria if studies i) focused on mental health outcomes such as depression and/or anxiety; conduct problems in terms of aggression and/or hyperactivity; emotional distress resulting in sadness and/ or social withdrawal as indications of psychosocial outcomes due to pandemic-related school closures; ii) included a sample of children age six to 13 years; iii) focused on children in remote learning or in quarantine; iv) were written in English or German; v) were published in early 2020 until present time; vi) had an observational study design such as cross-sectional studies, case-control studies, cohort studies; vii) collected quantitative data; viii) measured outcomes by selfreport through parents and/or children. Within the scope of this review, outcomes have been defined as psychosocial if linked with familial characteristics that children were facing over the period of remote learning. Studies were included if familial conditions encompassed any of the following: parental stress, parental depression, parenting style, parent-child interaction or domestic violence. Excluded studies referring only to pandemic related outcomes in children and studies probing mental health outcomes, child behavior and emotional distress unrelated to familial conditions. Commentaries, meta-analyses, editorials, opinion pieces, debates, conference protocols, as well as systematic reviews were excluded from reviewing. Studies were considered ineligible if the sample consisted of children attending boarding school or if applicable specialized schools due to cognitive disorders. Mixed method study types, collecting qualitative data on measures of interest, were excluded as well.

\section{Databases and Search Strategy}

For a broad search of primary studies, a team of two reviewers was formed. An electronic database search was conducted between June $6^{\text {th }}$ and June $19^{\text {th }}$ 2021 using: a) Ebscohost including Academic Search Ultimate, Bibliography of Asian Studies, CINAHL, ERIC, MEDLINE, APA PsycArticles, APA PsycInfo, PSYNDEX, SocINDEX, Teacher Reference Center; b) PubMed; c) Web of Science; d) ProQuest; e) Google Scholar, as a source for grey literature. Another two journals were searched for eligible records in addition to electronic databases To avoid publication-bias: a) The Lancet Psychiatry; b) BMC Public Health. Furthermore, the scientific platform Science Direct was searched for eligible literature, along with reference lists of primary studies and 
reviews in order to identify studies of further interest. Finally, selected experts from the field were contacted to gather unpublished and ongoing research. Since research on pandemic-related school closures and mental health of children and adolescents is a matter of current public awareness and evolving fast, a re-run of the electronic database search (EbscoHost, Pubmed, Web of Science, ProQuest, Google Scholar) was conducted on July $29^{\text {th }} 2021$ to ensure no recent studies were missed. The timescale of updated searches was June $19^{\text {th }}$ until July $29^{\text {th }} 2021$. Keywords were linked through Boolean operators 'AND' and 'OR'. Detailed key- word searches with or without restrictions for electronic databases, journals, and scientific platforms can be requested from the authors.

\section{Process of Study Selection}

The articles retrieved from the database search $(n=2,195)$ were exported into endnote and screened for duplicates using the remove duplicates function. A total of 456 duplicates were identified and removed. The title and abstract of the remaining 1,739 records were then screened according to the established inclusion and exclusion criteria, with a total of 47 articles that met inclusion criteria included. Of these 47 articles, eight articles were retained during the full-text screening process. The articles retrieved from databases (June and July 2021) and through other methods resulted in a total of 482 records, comprising of 419 records from both electronic database searches in June and July 2021 and 63 records from other search methods such as journals $(n=33)$ and a scientific platform $(n=30)$. Records obtained from journals (The Lancet, BMC Public Health) and the platform Science Direct were manually screened for duplicates as well as records found on electronic databases in July 2021. Additional studies were searched via the backward reference search. Ultimately, there were no additional eligible records found through reference lists of reviews and primary studies. The articles retrieved from the electronic database search in June $2021(n=355)$ were exported to Covidence (https://www.covidence.org) and automatically screened for duplicates. A total of 82 duplicates were identified and removed. In stage one of the selection process, title and - if available - abstract of the remaining 273 records were screened according to the pre-determined inclusion and exclusion criteria. Another 22 duplicate studies were removed manually from a total of
64 records generated on databases in July 2021. Ultimately, out of 315 records identified through electronic databases, 251 records were not relevant on review of the title and abstract and thus excluded. The remaining 64 reports were retrieved and assessed by examining the entire report carefully for eligibility. Based on titles and abstracts, a total of 64 reports met inclusion criteria, out of which 30 were randomly selected for further assessment of eligibility against inclusion and exclusion criteria by two independent researchers. Any disagreement regarding inclusion was discussed and resolved by consensus. To ensure reliability of the selection process Cohen's Kappa was computed $(\kappa=0.84)$ indicating an almost perfect agreement on titles and abstracts of the selected studies between assessors (interrater reliability). Subsequently, the full text screening of potentially eligible primary studies was conducted by one reviewer and respectively decisions about their inclusion. The entire process of study screening and final inclusion, following the revised PRISMA statement (Page et al., 2021), is presented in a flow chart (Fig. 1).

Of the remaining 64 references obtained from databases in June and July 2021, 14 did not include a population of subjects between age six and 13 or entirely included children with disorders such as autism; 13 reported irrelevant outcomes or measures; six were studies collecting only qualitative data; 14 were not relevant empirical studies (commentaries, letter to the editor); four were based on a wrong setting (returning to school), and finally three studies collected data from public authorities. In addition to the database identification, reports were searched in journals, one scientific platform and reference lists of a few reviews and primary studies. The search through other methods comprised 63 records, of which 14 duplicates were removed manually. A total of 42 reports were sought for retrieval and assessed for eligibility. None of the reports met the selection criteria out of various reasons presented in the PRISMA flow chart (Fig. 1).

Studies, which appeared to meet inclusion criteria were, i.e. one study by McKune et al. (2021) measuring psychosocial outcomes among K-12 students with a subsample of primary students in Florida, USA. This study was excluded, since depressive, anxiety, and OCD symptoms in children were rather associated with parental knowledge, attitudes, and practice towards COVID-19, than psychological characteristics of parents. Another excluded study by Monnier et al. (2021) used data from different child 


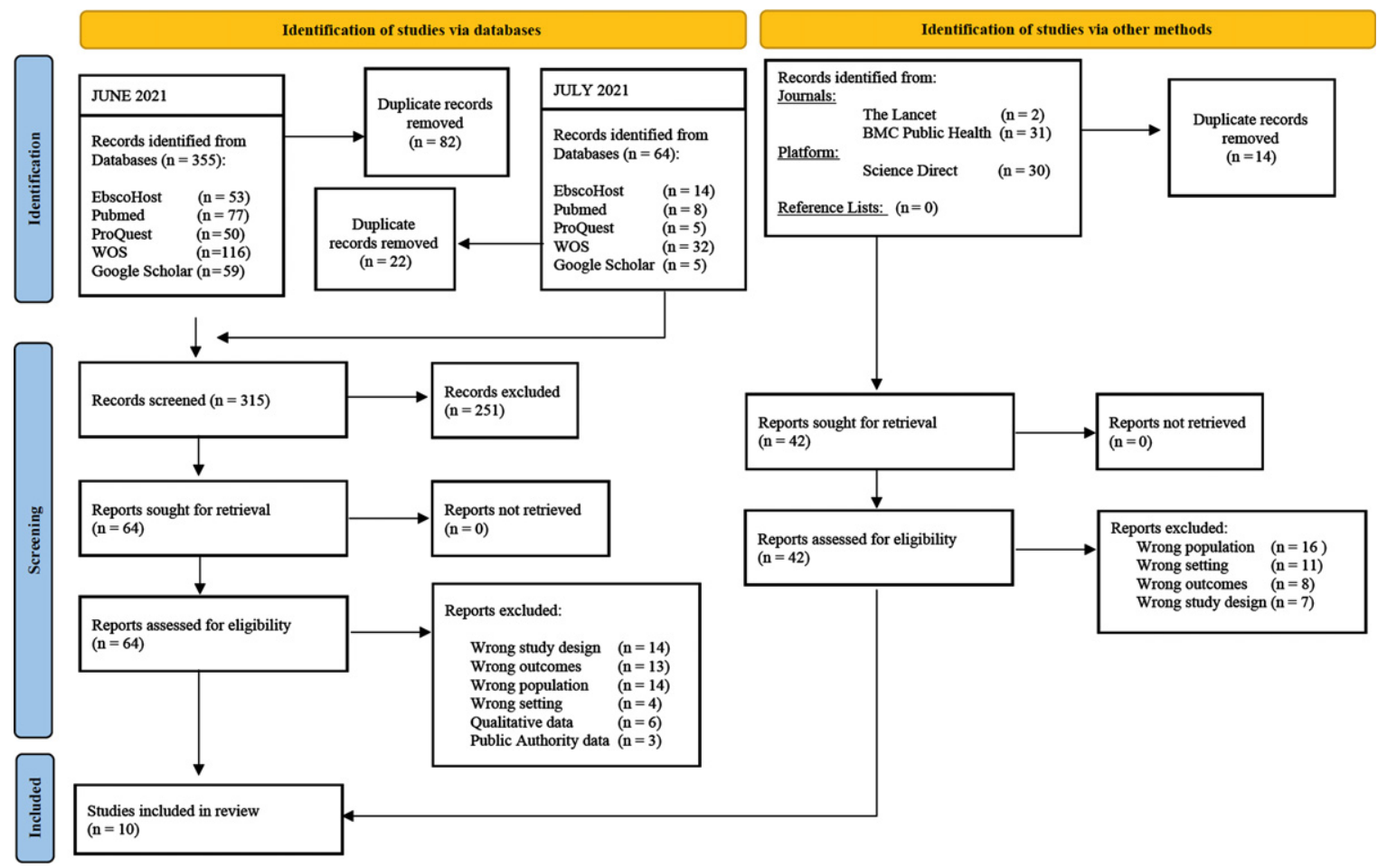

Figure 1. PRISMA flow chart.

and adult cohorts generated by the French SAPRIS Project, measuring health, social interactions, and socio-economic characteristics of the general population during the COVID-19 crisis in France. In their study, Monnier et al. (2021) investigated the association between the mental health of children (age 8 to 9) and social characteristics of their families during school closure, which did not meet the present review's pre-determined psychosocial factors and was therefore rejected. In a German nationally representative cross-sectional study by Calvano et al. (2021), the role of parental stress and mental health of parents for the pandemic-related occurrence and increase of adverse childhood events (e.g. violence, neglect, abuse against children) was analyzed; certainly with no further investigation on psychosocial health outcomes in children during school closure, which led to the exclusion of the study. In a nationally representative survey, Gadermann et al. (2021) probed the pandemic-related change of parent-child interactions within Canadian families. This crosssectional study was excluded from reviewing, since Gadermann et al. (2021) put the focus entirely on the quality of parent-child interactions during the COVID-19 pandemic and ignored psychosocial out- comes in children as a potential result of parent-child interaction due to school closures.

Thus, the screening process resulted in a total of 10 studies included in this review (Cellini et al., 2021; Domínguez-Álvarez et al., 2020; Larsen et al., 2021; Lee et al., 2021; McMahon et al., 2021; Morgül et al., 2020; Moulin et al., 2021; Takahashi \& Honda, 2021; Tang et al., 2021; Tso et al., 2020).

\section{Data Extraction}

Relevant information of selected primary studies was retrieved and gathered using a coding protocol. The coding protocol comprised relevant data from each included study on: a) General information: author, article title, date of publication, country of origin; b) Study characteristics: aim/objectives of the study, number and age of participants, type of study, duration of study, length of school closure or quarantine, method/ measurement tool used in the study, psychosocial factors assessed (familial conditions), outcomes assessed (depression, anxiety, sadness, social withdrawal, hyperactivity, aggression, conduct problems); c) Results: outcomes and significant findings. Data extraction of the final sample 
of included primary studies was carried out and collected by one reviewer. To avoid risk of bias assessment a sample of five studies of included studies was pilot tested and assessed independently by another reviewer following the coding protocol. Both reviewers reviewed general information, study characteristics and results, and reached a consensus about the most accurate organization of measures and results. Cohen's Kappa was assessed $(\kappa=0.69)$ indicating a substantial agreement on extracted data between both assessors (interrater reliability). This ensured extracted data provided the required information for subsequent data synthesis.

\section{Quality Assessment of Primary Studies}

To minimize bias and avoid an under- or overestimation of results presented in the studies, the quality of each included study was assessed by one reviewer using the Downs and Black Checklist (Downs \& Black, 1998), which is a methodological quality rating instrument created for randomized and non-randomized studies in a systematic review or meta-analysis. The Downs and Black Checklist comprises five sub-scales with overall 27 items, which in sum provide both an overall score for study quality as well as scores for the subscales: quality of reporting, bias and confounding (internal validity), external validity and power. Answers are scored 0 or 1, except for one item in the reporting subscale, which is scored 0 to 2 . In their review Hooper et al. (2008) power item responses were collapsed from the original 0 to 5 , to either 0 or 1 , meaning the total maximum score is 28 instead of 31 . Score ranges were given corresponding quality levels (Hooper et al., 2008): excellent (26-28); good (20-25); fair (15-19); and poor ( $\leq 14)$. Studies with poor quality were not removed from the total sample of primary studies and instead reported in the review.

\section{Synthesis of Results}

A narrative synthesis was carried out to integrate findings from quantitative studies within the following categories: (1) characteristics of included studies, (2) the impact of school closures on children's mental health associated with psychosocial factors within the family environment, (3) the impact of school closures on child behavior associated with psychosocial factors within the family environment, (4) the impact of school closures on children's emotional distress associated with psychosocial factors within the fam- ily environment, (5) the further comparison between longitudinal data and cross-sectional data, (6) differences and similarities in the findings across all studies within this review, which indicate whether results are consistent (homogeneous) or inconsistent (heterogeneous) with one another.

\section{Results}

\section{Study Characteristics}

The final sample of 10 primary studies comprised of seven cross-sectional studies (Cellini et al., 2021; Domínguez-Álvarez et al., 2020; Lee et al., 2021; McMahon et al., 2021; Morgül et al., 2020; Tang et al., 2021; Tso et al., 2020) and 3 cohort studies (Larsen et al., 2021; Moulin et al., 2021; Takahashi \& Honda, 2021). Out of included cohort studies, one study collected longitudinal data (Takahashi \& Honda, 2021). Relevant data were quantitative. It should be noted that one study caused discrepancies as one measure was qualitatively analyzed (Lee et al., 2021) and therefore considered a mixed method study type according to selection criteria. However, both reviewers discussed inclusion and reached consensus to keep the study because the measure was unrelated to familial characteristics, hence irrelevant to this reviews' research question. Of the final studies, two studies included a full sample with children age seven to 11 (Larsen et al., 2021) and children age six to 10 (Cellini et al., 2021); six studies included subsamples within the pre-determined age range of six and 13 years (Domínguez-Álvarez et al., 2020; Lee et al., 2021; McMahon et al., 2021; Morgül et al., 2020; Tang et al., 2021; Takahashi \& Honda, 2021; Tso et al., 2020); two studies did not determine subsamples (Lee et al., 2021; McMahon et al., 2021). The mean age ranged from a minimum of 6.8 years (Moulin et al., 2021) to a maximum of 12.41 years (Takahashi \& Honda, 2021). Mean age range was based on nine studies; one study did not report on the mean age of their sample (Lee et al., 2021). Across all studies, subjects of interest and their families were experiencing pandemic-related school closures and remote learning or the mandatory national quarantine period, imposing school closures during the first wave of the COVID-19 pandemic in 2020. Data were collected through online surveys and completed by parents (Domínguez-Álvarez et al., 2020; Lee et al., 2021; McMahon et al., 2021; Morgül et al., 2020; Moulin et al., 2021; Takahashi \& Honda, 2021; Tso 
et al., 2020) or children (Larsen et al., 2021; Tang et al., 2021), or explicitly by mothers (Cellini et al., 2021). As for measured main outcomes in children, these articles focused on psychological difficulties in children, such as emotional problems and/or conduct problems and/or hyperactivity (Cellini et al., 2021; Domínguez-Álvarez et al., 2020; McMahon et al., 2021; Morgül et al., 2020; Moulin et al., 2021; Takahashi \& Honda, 2021; Tso et al., 2020); on children's depressive and/or anxiety symptoms (Lee et al., 2021; Tang et al., 2021); on emotional, cognitive/somatic reactions of children (Larsen et al., 2021). Assessed psychosocial factors within the familial environment linked to children's psychosocial health were parental depression (Lee et al., 2021; McMahon et al., 2021; Morgül et al., 2020; Takahashi \& Honda, 2021; Tso et al., 2020), maternal depression (Cellini et al., 2021), parent-child interaction (Tang et al. 2021; Tso et al., 2020) parental stress (Domínguez-Álvarez et al., 2020; McMahon et al., 2021; Tso et al., 2020). Notably, Domínguez-Álvarez et al. (2020) measured parental dispositional resilience; in the context of this review a lower level of resilience is understood as predictor of stress (Southwick et al., 2005). In addition to the psychosocial factors of interest, Cellini et al. (2021) assessed maternal difficulties in emotion regulation; Domínguez-Álvarez et al. (2020) measured the pandemic-related stressor of parental fear of future; Lee et al. (2021) included the measure of parental anxiety and as well parenting stress. Even if these measures did not directly account for the predetermined psychosocial factors; however, they were taken into account and rather understood as valuable indices of psychometric properties in primary caregivers. Details on characteristics of the included studies are presented in Table 1.

\section{Study Quality Assessment}

Table 2 summarizes the quality of the 10 studies included. Their quality scores ranged from 12 to 23 , with an average of 19.6 score points. Based on the Downs and Black Scale Scores, seven studies were rated good (Cellini et al., 2021; Domínguez-Álvarez et al., 2020; Larsen et al., 2021; Lee et al., 2021; McMahon et al., 2021; Takahashi \& Honda, 2021; Tang et al., 2021), two were rated fair (Moulin et al., 2021; Tso et al., 2020), and one was rated poor (Morgül et al. 2020). The detailed assessment of each study using the Downs and Black Scale (1998) can be obtained from the authors.

\section{Data Synthesis}

Children's mental health and associated psychosocial factors

Within the setting of homeschooling, data from three studies (Lee et al., 2021; McMahon et al., 2021; Tang et al., 2021) revealed effects on children showing poorer mental health related to familial characteristics. Variables such as parenting stress; moderate to severe anxiety in parents were associated with higher anxiety levels in children (Lee et al., 2021). Specifically parenting stress was significantly related to children's anxiety level $(\beta=0.40$; $p<0.001$ ) (Lee et al., 2021). In contrast to these findings, parents suffering from depression did not significantly impact children's mental health during quarantine, albeit $40 \%$ of participating parents met criteria for major depression according to PHQ-8 (Lee et al., 2021). Mental health outcomes were predicted by parent-child discussion about COVID-19, established during home confinement (Tang et al., 2021). Children reported to feel less anxious and less depressive if both parents and children were more frequently engaged in comforting discussions about the adverse event of COVID-19 with one another. A high frequency of parent-child discussion was related to less likelihood of occurring depressive symptoms as well as anxiety symptoms (Tang et al., 2021). The interaction between finding quarantine not beneficial and parent-child discussion revealed a significant but less pronounced effect on children's mental health. Children who did not enjoy the time spent in quarantine felt less depressed and anxious if parents were available for conversations. One study took a perspective on children's mental health status, depending on the ability in parents to support a child to complete schoolwork during quarantine, which was mediated by psychological distress (McMahon et al., 2021). Children displayed signs of mental health impairments if their parents were less prone to provide support due to their own psychological distress (McMahon et al., 2021).

\section{Children's emotional distress and associated psy- chosocial factors}

A total of seven studies explicitly analyzed children's emotional distress during school closures (Cellini et al., 2021; Domínguez-Álvarez et al., 2020; Larsen et al., 2021; Morgül et al., 2020; Moulin et al., 2021; Takahashi \& Honda, 2021; Tso et al., 
Table 1

Data Extraction and Coding Protocol

\begin{tabular}{|c|c|c|c|c|c|c|c|c|}
\hline $\begin{array}{l}\text { Author (Year) } \\
\text { Country } \\
\text { Journal }\end{array}$ & $\begin{array}{l}\text { Study } \\
\text { type }\end{array}$ & Aim/Objective of study & $\begin{array}{l}\text { Study } \\
\text { population } \\
\text { children }\end{array}$ & $\begin{array}{l}\text { Length of data } \\
\text { collection/ } \\
\text { Length of } \\
\text { school closure }\end{array}$ & $\begin{array}{l}\text { Method/ } \\
\text { Measurement } \\
\text { tool }\end{array}$ & $\begin{array}{l}\text { Psychosocial } \\
\text { factors assessed }\end{array}$ & $\begin{array}{l}\text { Outcomes } \\
\text { assessed }\end{array}$ & $\begin{array}{l}\text { Findings relevant to research } \\
\text { question }\end{array}$ \\
\hline Larsen (2021) & $\begin{array}{l}\text { Cohort } \\
\text { study }\end{array}$ & $\begin{array}{l}\text { Children's emotional, } \\
\text { cognitive \& somatic }\end{array}$ & $n=442$ & $\begin{array}{l}\text { April } 1 \text { to May } \\
25,2020\end{array}$ & Child report & \multirow{4}{*}{$\begin{array}{l}\text { Perceived family } \\
\text { stress \& instability } \\
\text { by children }\end{array}$} & $\begin{array}{l}\text { Emotional } \\
\text { reactions }\end{array}$ & Hierarchal Regression Analysis \\
\hline Norway & & $\begin{array}{l}\text { reactions relating to } \\
\text { perceived stress \& }\end{array}$ & age $7-11$ & $\begin{array}{l}\text { School } \\
\text { closure: }\end{array}$ & \multirow{3}{*}{$\begin{array}{l}\text { self- } \\
\text { constructed } \\
\text { items }\end{array}$} & & \multirow[t]{3}{*}{$\begin{array}{l}\text { Cognitive/Somatic } \\
\text { reactions }\end{array}$} & $\begin{array}{l}\text { Perceived family Stress \& } \\
\text { Instability }\end{array}$ \\
\hline $\begin{array}{l}\text { European } \\
\text { Child \& } \\
\text { Adolescent }\end{array}$ & & $\begin{array}{l}\text { instability within the } \\
\text { family, home school } \\
\text { experience, screen time }\end{array}$ & years & \multirow[t]{2}{*}{$\begin{array}{l}\text { March } 12 \text { to } \\
\text { April 27, } 2020\end{array}$} & & & & \multirow{2}{*}{$\begin{array}{l}\text { Higher levels of stress \& } \\
\text { instability } \rightarrow \text { higher reaction } \\
\text { level } \\
\text { Emotional Reactions } \\
B=0.569, \text { SE } B=0.040, \\
B=0.555, p<0.001 \\
\text { Somatic/Cognitive Reactions } \\
B=0.375, \text { SE } B=0.045, \\
B=0.356, p<0.001\end{array}$} \\
\hline Health & & $\begin{array}{l}\text { use, missing friends, } \\
\text { worry about virus } \\
\text { infection. }\end{array}$ & $S D=2.59$ & & & & & \\
\hline Lee (2021) & $\begin{array}{l}\text { Cross- } \\
\text { sectional } \\
\text { Study }\end{array}$ & $\begin{array}{l}\text { Investigation of } \\
\text { parent-child dynamics } \\
\text { during COVID-19 related } \\
\text { school closures. }\end{array}$ & $n=405$ & April 2, 2020 & $\begin{array}{l}\text { Parent report } \\
\text { online survey } \\
\text { with items } \\
\text { from }\end{array}$ & $\begin{array}{l}\text { Parental } \\
\text { depression (1) }\end{array}$ & Child anxiety (2) & $\begin{array}{l}\text { Multivariate Regression models: } \\
\text { Parents with moderate/ severe } \\
\text { anxiety and higher child Anxiety } \\
\text { scores }\end{array}$ \\
\hline USA & & & age $0-12$ & $\begin{array}{l}\text { School } \\
\text { closure: }\end{array}$ & PHQ-8 *(1) & $\begin{array}{l}\text { Parental anxiety } \\
\text { (3) }\end{array}$ & & $\begin{array}{l}B=0.17,95 \% \mathrm{CI}=[0.06,0.28] \\
p=0.002\end{array}$ \\
\hline \multirow{5}{*}{$\begin{array}{l}\text { Children and } \\
\text { Youth Services } \\
\text { Review }\end{array}$} & & & \multirow{5}{*}{$\begin{array}{l}\text { no age } \\
\text { subgroups } \\
\text { children }\end{array}$} & $\begin{array}{l}M_{l \text { ockdown }} \\
\text { days }=19.58\end{array}$ & $\begin{array}{l}\text { Child } \\
\text { Behavior }\end{array}$ & \multirow[t]{5}{*}{$\begin{array}{l}\text { Parenting Stress } \\
\text { (4) }\end{array}$} & & $\begin{array}{l}\text { Parental depression and higher } \\
\text { child anxiety scores }\end{array}$ \\
\hline & & & & & Checklist * (2) & & & $ß=0.10,95 \% \mathrm{CI}=[-0.01,0.21]$ \\
\hline & & & & $\mathrm{SD}=10.67$ & GAD-7 *(3) & & & $p=0.071$ \\
\hline & & & & & Parenting & & & Parenting Stress and child anxiety \\
\hline & & & & & $\begin{array}{l}\text { Scale of } \\
\text { FFCWS } *(4)\end{array}$ & & & $\begin{array}{l}\beta=0.40,95 \% \mathrm{CI}=[0.32,0.48] \\
p<0.001\end{array}$ \\
\hline
\end{tabular}


Table 1

Continued

\begin{tabular}{|c|c|c|c|c|c|c|c|c|}
\hline $\begin{array}{l}\text { Author (Year) } \\
\text { Country } \\
\text { Journal }\end{array}$ & $\begin{array}{l}\text { Study } \\
\text { type }\end{array}$ & Aim/Objective of study & $\begin{array}{l}\text { Study } \\
\text { population } \\
\text { children }\end{array}$ & $\begin{array}{l}\text { Length of data } \\
\text { collection/ } \\
\text { Length of } \\
\text { school closure }\end{array}$ & $\begin{array}{l}\text { Method/ } \\
\text { Measurement } \\
\text { tool }\end{array}$ & $\begin{array}{l}\text { Psychosocial } \\
\text { factors assessed }\end{array}$ & $\begin{array}{l}\text { Outcomes } \\
\text { assessed }\end{array}$ & $\begin{array}{l}\text { Findings relevant to research } \\
\text { question }\end{array}$ \\
\hline $\begin{array}{l}\text { Domínguez- } \\
\text { Álvarez } \\
(2020)\end{array}$ & \multirow[t]{5}{*}{$\begin{array}{l}\text { Cross- } \\
\text { sec- } \\
\text { tional } \\
\text { Study }\end{array}$} & \multirow{5}{*}{$\begin{array}{l}\text { How child coping, } \\
\text { contextual conditions and } \\
\text { parental dispositional } \\
\text { resilience might } \\
\text { contribute to psychosocial } \\
\text { adjustment during } \\
\text { COVID-19 pandemic. }\end{array}$} & $n=1,123$ & $\begin{array}{l}\text { April 8-April } \\
27,2020\end{array}$ & $\begin{array}{l}\text { Parent report } \\
\text { online Survey } \\
\text { with items } \\
\text { from }\end{array}$ & $\begin{array}{l}\text { Parental } \\
\text { dispositional } \\
\text { Resilience (3) }\end{array}$ & $\begin{array}{l}\text { Child } \\
\text { maladjustment } \\
\text { (2): }\end{array}$ & $\begin{array}{l}\text { Parental fear of future positively } \\
\text { correlated with } \\
\text { CON }(r=0.14, p=0.001) \\
\text { HYP }(r=0.17, p=0.001)\end{array}$ \\
\hline Spain & & & age $3-12$ & $\begin{array}{l}\text { School } \\
\text { closure: }\end{array}$ & SDQ *(2) & $\begin{array}{l}\text { Parental fear of } \\
\text { future as } \\
\text { COVID-19 related } \\
\text { stressor (4) }\end{array}$ & $\begin{array}{l}\text { Conduct } \\
\text { problems, } \\
\text { Emotional } \\
\text { problems, } \\
\text { Hyperactivity }\end{array}$ & $\begin{array}{l}\text { EMO }(r=0.13, p=0.001) \\
\text { Parental dispositional resilience } \\
\text { negatively correlated with } \\
\text { CON }(r=-0.20, p=0.001) \\
\operatorname{HYP}(r=-0.21, p=0.001)\end{array}$ \\
\hline \multirow[t]{3}{*}{$\begin{array}{l}\text { Frontiers In } \\
\text { Psychology }\end{array}$} & & & subgroups: & $\begin{array}{l}\text { March } 13 \\
\text {-April 26, } \\
2020\end{array}$ & $\begin{array}{l}\text { CD-RISC-10 } \\
*(3)\end{array}$ & & $\begin{array}{l}\text { Child coping } \\
\text { strategies (1): } \\
\text { engagement or }\end{array}$ & $\begin{array}{l}\text { EMO }(r=-0.18, p=0.001) \\
\text { Multiple regression analysis: } \\
\text { Parental dispositional resilience }\end{array}$ \\
\hline & & & $\begin{array}{l}n=393 \\
\text { age } 7-9 \\
M_{\text {age }}=7.98 \\
S D=0.83 \\
\\
n=248 \\
\text { age } 10-12 \\
M_{\text {age }}=10.62 \\
S D=0.67\end{array}$ & $\begin{array}{l}M_{\text {confinement }}= \\
30.87 \text { days }\end{array}$ & $\begin{array}{l}\text { KidCOPE *(1) } \\
\text { The Children's } \\
\text { Coping } \\
\text { Checklist *(1) } \\
\text { AD hoc } \\
\text { created item } \\
*(4)\end{array}$ & & disengagement & $\begin{array}{l}\text { negatively associated with } \\
\text { CON }(B=-0.09, p<0.05) \\
\text { HYP }(B=-0.11, p<0.001) \\
\text { EMO }(B=-0.09, p<0.05) \\
\text { Interaction effects } \\
\text { higher levels of parent perceived } \\
\text { fear predicted higher levels of } \\
\text { child behavioral }(B=0.13, \\
p<0.04) \& \text { emotional problems } \\
(\beta=0.14, p<0.03) \text { when children } \\
\text { displayed disengagement }\end{array}$ \\
\hline & & & & & & & & $\begin{array}{l}\text { lower levels of parent resilience } \\
\text { predicted higher levels of } \\
\text { emotional problems }(B=-0.07 \text {, } \\
p<0.02) \text { when children displayed } \\
\text { disengagement }\end{array}$ \\
\hline
\end{tabular}




\begin{tabular}{|c|c|c|c|c|c|c|c|}
\hline $\begin{array}{l}\text { McMahon } \\
(2021)\end{array}$ & $\begin{array}{l}\text { Cross- } \\
\text { Sectional }\end{array}$ & $\begin{array}{l}\text { How parents and primary } \\
\text { school children cope with }\end{array}$ & $n=797$ & $\begin{array}{l}\text { Between April } \\
\text { and May } 2020\end{array}$ & $\begin{array}{l}\text { Parent report } \\
\text { online survey }\end{array}$ & $\begin{array}{l}\text { Parent } \\
\text { psychological }\end{array}$ & $\begin{array}{l}\text { Mental health } \\
\text { status (1) }\end{array}$ \\
\hline Studies & Study & $\begin{array}{l}\text { pandemic related school } \\
\text { closures and how it is }\end{array}$ & & 3 weeks & $\begin{array}{l}\text { with items } \\
\text { from }\end{array}$ & $\begin{array}{l}\text { distress (2) } \\
\text { mediating }\end{array}$ & \\
\hline Ireland & & $\begin{array}{l}\text { correlated with children's } \\
\text { mental health; how the } \\
\text { parental ability to manage }\end{array}$ & age $4-12$ & $\begin{array}{l}\text { no precise date } \\
\text { given }\end{array}$ & SDQ *(1) & $\begin{array}{l}\text { parental ability to } \\
\text { support their child } \\
\text { with schoolwork }\end{array}$ & \\
\hline $\begin{array}{l}\text { Irish } \\
\text { Educational }\end{array}$ & & $\begin{array}{l}\text { the transition to remote } \\
\text { learning and its's impact } \\
\text { on child mental health } \\
\text { status. }\end{array}$ & $M_{\mathrm{age}}=9$ & $\begin{array}{l}\text { School } \\
\text { closure: }\end{array}$ & DASS- $21 *(2)$ & & \\
\hline
\end{tabular}

Multiple regression

analysis:

Parental psychological distress positively associated with child mental health status $(B=3.31$, $p \leq 0.001$ )

Less ability to support their child negatively associated with mental health status $(B=-1.33$,

$p \leq 0.003$ )

Mediation effect:

parental psychological distress mediates relationship between ability to support child and

mental health status $(b=-1.44$, $t(675)=-5.12, p<0.001)$

Direct effect of Parental

psychological distress on mental

health status $(B=0.14$,

$t(676)=12.49, p<0.001)$ 
Table 1

Continued

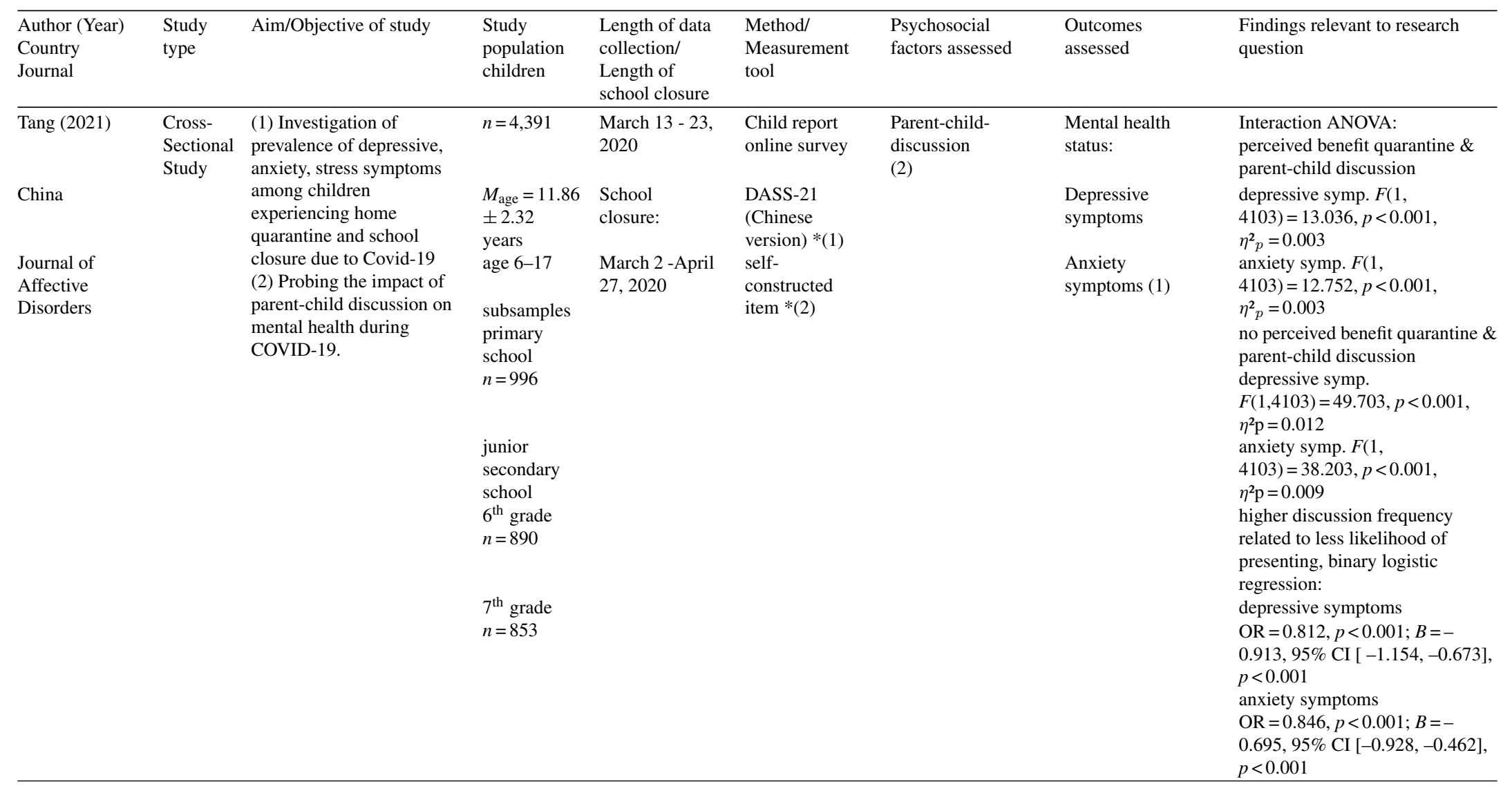




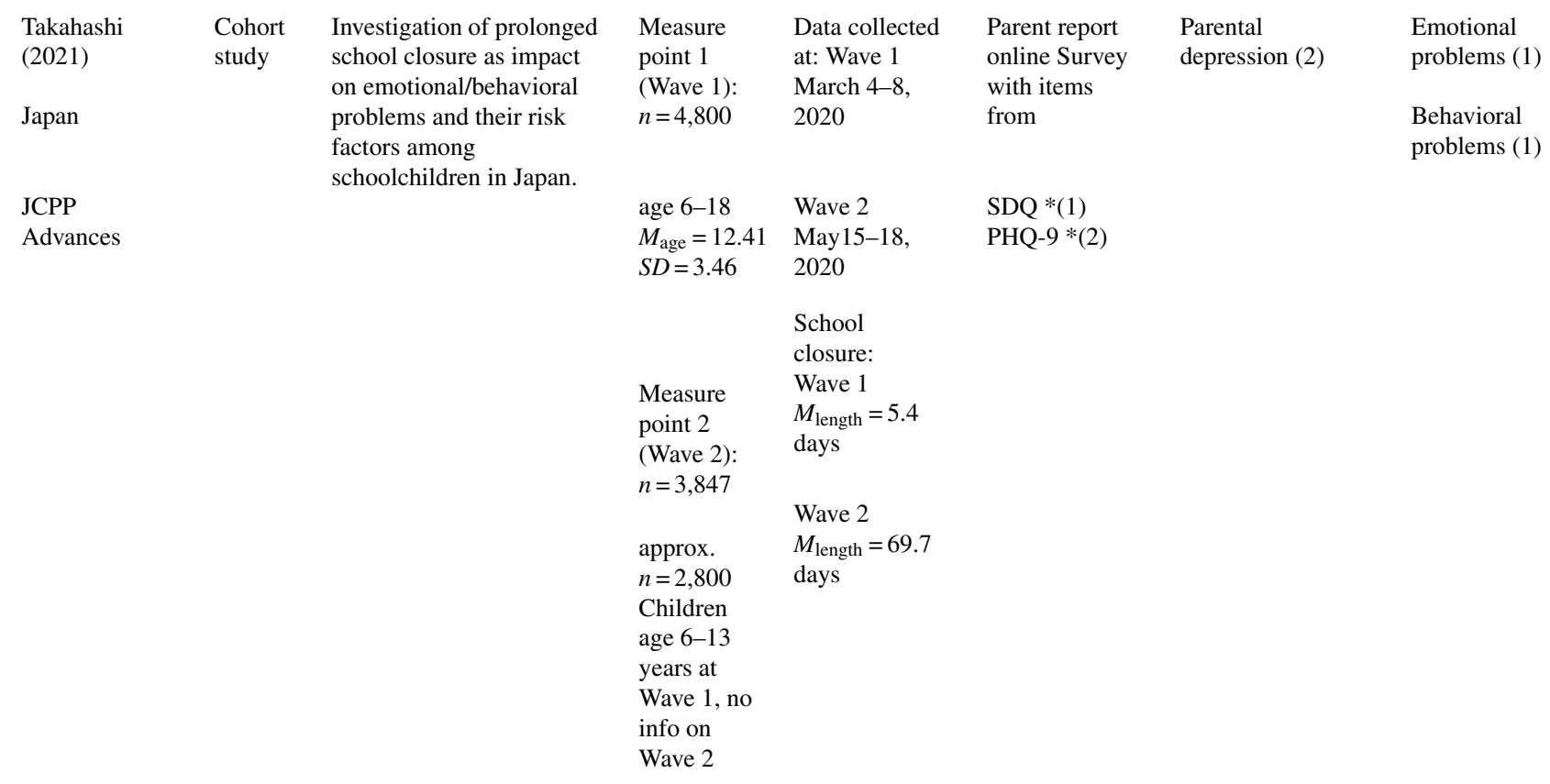
depression increased from Wave

1 to Wave $2(1.5 \%$ vs. $3.5 \%)$

Clinical levels on SDQ

dimensions increased from Wave 1 to Wave 2

Emotional problems: $18.7 \%$ vs. $23.7 \%$

Conduct problems: $17.2 \%$ vs. $21.9 \%$

Hyperactivity/inattention: $21.0 \%$

vs. $34.6 \%$

Risk factor parental depression responsible for increase in

Children's emotional/behavioral problems

Logistic regression analysis

Parental depression at Wave 2

was associated with SDQ dimensions at Wave 2:

$\mathrm{EMO} \mathrm{OR}=1.11,95 \% \mathrm{CI}$

[1.19-1.14], $p<0.001$

$\mathrm{CON}$ OR $=1.10,95 \% \mathrm{CI}$

[1.07-1.13], $p<0.001$

HYP OR $=1.07,95 \%$

[1.05-1.10], $p<0.001$

Association between parenta

depression at Wave 1 and

problem subscales not mentioned 
Table 1

(Continued)

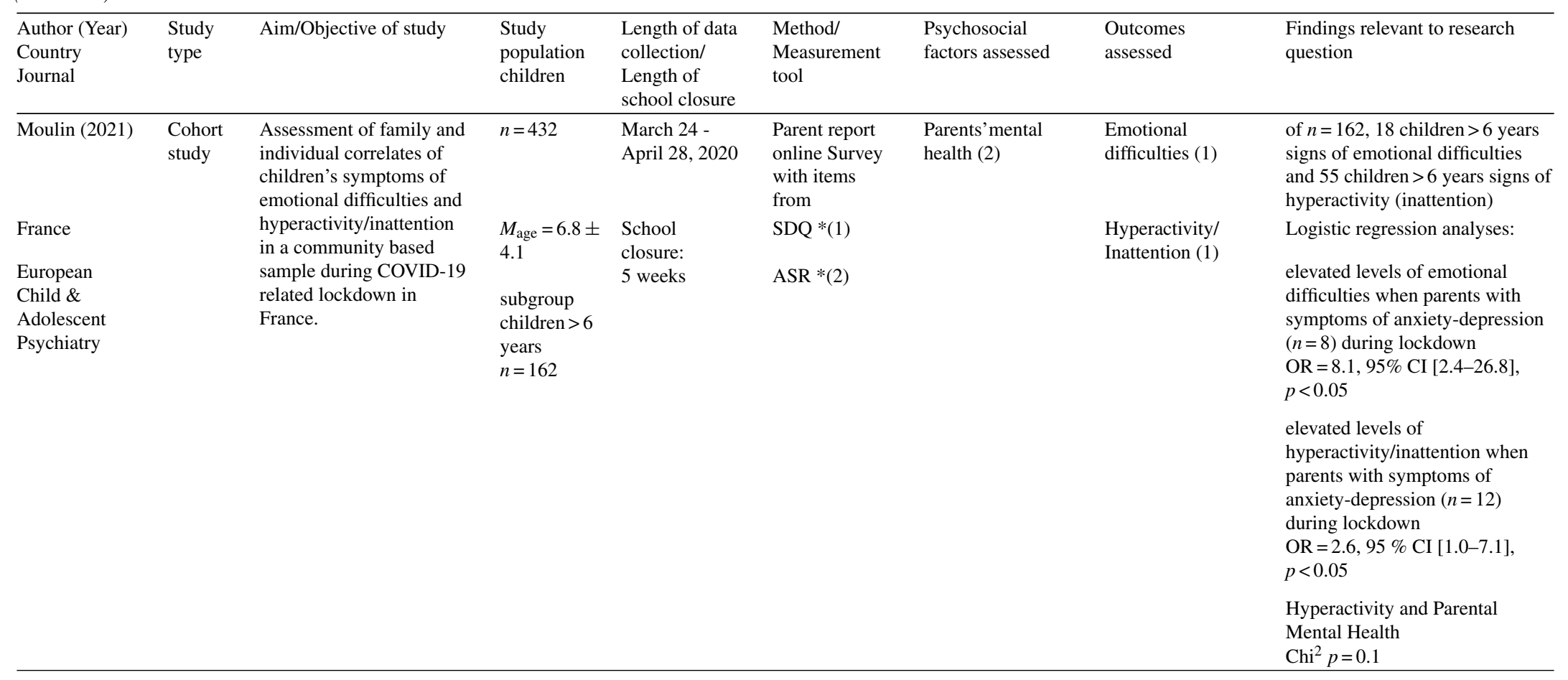




$\begin{array}{lll}\begin{array}{ll}\text { Cross- } \\ \text { sectional } \\ \text { study }\end{array} & \begin{array}{l}\text { Investigation and } \\ \text { identification of (1) the } \\ \text { characteristics of children } \\ \text { and their parents }\end{array} & n=29,202 \\ & \text { vulnerable to the negative } & \\ & \text { age 2-12 } \\ & \text { impacts of the COVID-19 } & \\ & \text { pandemic and its related } & \text { subsamples } \\ & \text { school closures and (2) } & \text { age 6-12 } \\ & \text { factors that can promote } & n=17,029 \\ & \text { resilience. } & M_{\text {age }}=8.51 \\ & & S D=1.86\end{array}$

Completion of surveys in late March 2020

No further

information

European

Child \&

Adolescent

Psychiatry
Parent report online Survey with items

from

SDQ *(1)

CPCIS *(2)

PSS *(4)

Item on health

profile of

parent*(5)
Parental Stress (4) Emotional problems (1)

Parent-Child Conduct problems

Interaction (2) (1)

Parental mental Hyperactivity/

disorders (5)

Inattention (1)
Linear regression models,

subgroup age 6-12:

SDQ \& PSS

higher parental stress

leading to higher SDQ

scores

EMO $(B=0.06, \beta=0.33$,

$p<0.001)$

$\mathrm{CON}(B=0.06, B=0.42$,

$p<0.001)$

HYP $(B=0.09, \beta=0.44$,

$p<0.001)$

Parent-child interaction, SDQ \&

CPCIS

Learning activities

$\operatorname{EMO}(B=-0.10, \beta=-0.04$

$p<0.001)$

$\operatorname{CON}(B=-0.15, \beta=-0.07$,

$p<0.001)$

$\operatorname{HYP}(B=-0.14, \beta=-0.05$,

$p<0.001)$

Recreational activitie

EMO $(B=-0.19, B=-0.07$,

$p<0.001)$

$\mathrm{CON}(B=-0.26, \beta=-0.12$,

$p<0.001)$

$\operatorname{HYP}(B=-0.54, \beta=-0.17$,

$p<0.001)$

parents with mental disorders

/SDQ:

maternal mental disorders

associated with higher scores in

$\mathrm{EMO}(B=0.71, \beta=0.40$,

$p<0.001)$

$\mathrm{CON}(B=0.52, \beta=0.33$,

$p<0.001)$

$\mathrm{HYP}(B=0.57, B=0.26$,

$p<0.001)$

paternal mental disorders

associated with higher scores in

EMO $(B=0.34, \beta=0.19$,

$p<0.001)$ 
Table 1

(Continued)

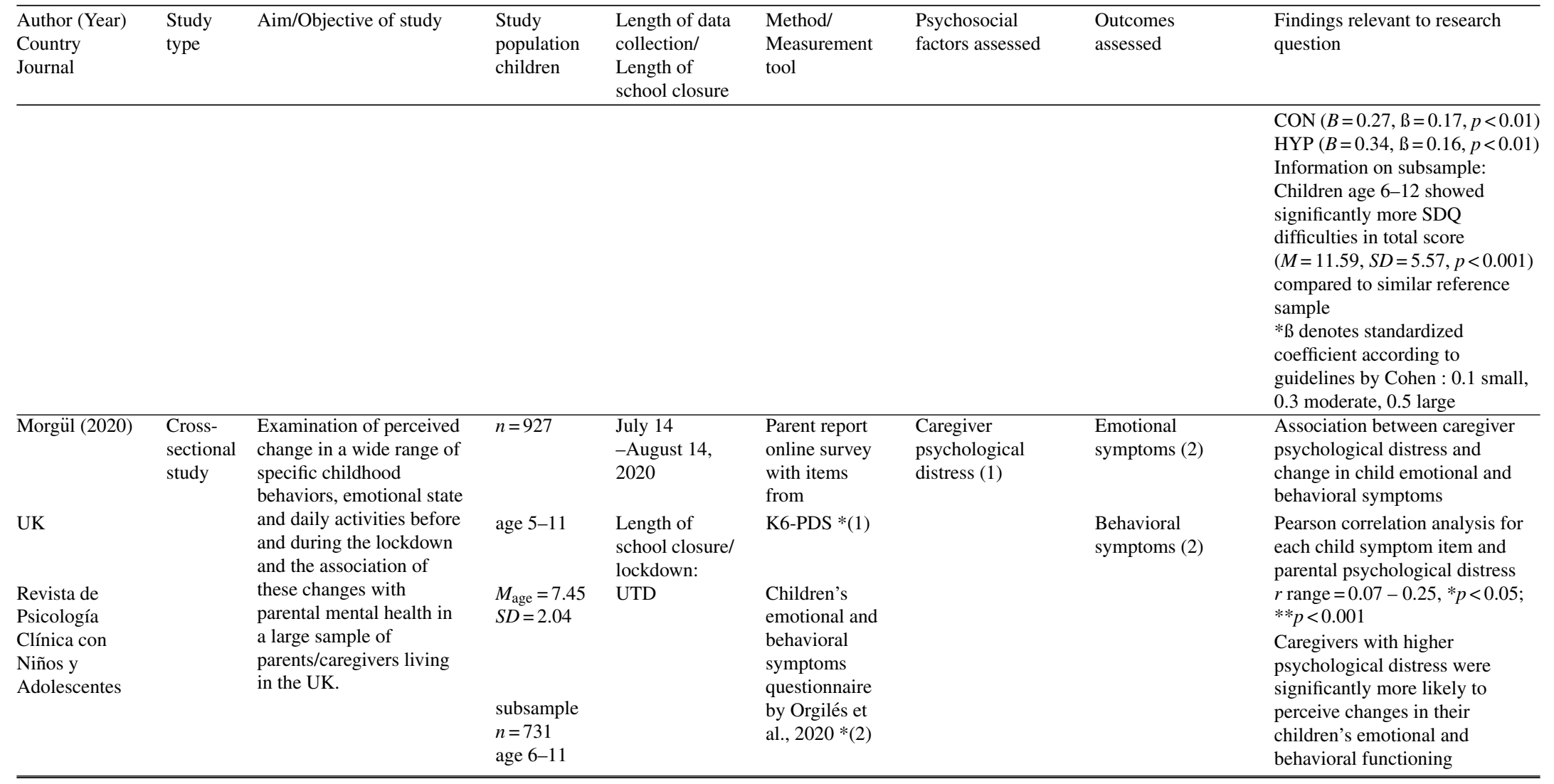




$\begin{array}{llcl}\begin{array}{l}\text { Cross- } \\ \text { Sectional } \\ \text { Study }\end{array} & \begin{array}{l}{[(1) \text { Investigation of how }} \\ \text { prolonged home } \\ \text { confinement during the } \\ \text { national lockdown has } \\ \text { impacted sleep in mothers } \\ \text { and their school-age } \\ \text { children in terms of } \\ \text { timing and quality]. }\end{array} & \text { age 6-10 } & \begin{array}{l}\text { School } \\ \text { closure: }\end{array} \\ \begin{array}{l}\text { (2) Investigation of the } \\ \text { relationship between } \\ \text { children's sleep and } \\ \text { changes in routine as well } \\ \text { as their psychological } \\ \text { difficulties taking into }\end{array} & & \\ \text { account their mothers } & & \\ \text { emotional symptoms. } & & \\ & & \\ \text { eme } & & \\ \end{array}$

Mother report online survey with items

from

SDQ-P (Italian version) $*(1)$

$\rightarrow$ resulting in PDS

(psychological

difficulties

score)

SDQ-18+*(2)

$\rightarrow$ resulting in

PDS+18

(psychological

difficulties

score)

DERS (Italian

version) $*(3)$
Psychological Children's

difficulties in psychological

mothers (2)

Difficulties in

Emotion

Regulation of

mothers (3) difficulties:

Emotional

problems (1)

Behavioral

problems (1)

Hyperactivity (1)
Linear mixed models

Mothers total DERS score

covaried positively with

children's emotional problems

$\left(F_{1,289}=14.29, p<0.001\right.$;

coefficient $=0.02, \mathrm{SE}=0.005$,

$t=3.78$ )

Mothers total DERS score

covaried positively with

children's conduct problems

$\left(F_{1,289}=14.68, p<0.001\right.$;

coefficient $=0.02, \mathrm{SE}=0.005$,

$t=3.83$ )

Mothers total DERS score

covaried positively with

children's hyperactivity

$\left(F_{1,289}=8.10, p=0.005\right.$;

coefficient $=0.01, \mathrm{SE}=0.004$,

$t=2.85$ )

Multiple linear regression model

Changes in children's PDS

predicted by PDS +18

$B=0.23,95 \% \mathrm{CI}=[0.13-0.33]$,

$B=0.23, t=4.67, p<0.001$ 
Table 2

Scores of Downs \& Black Scale

\begin{tabular}{lcccccr}
\hline $\begin{array}{l}\text { Studies } \\
\text { (Author) }\end{array}$ & Reporting & $\begin{array}{c}\text { External } \\
\text { Validity }\end{array}$ & $\begin{array}{c}\text { Internal } \\
\text { Validity } \\
\text { Bias }\end{array}$ & $\begin{array}{c}\text { Internal } \\
\text { Validity } \\
\text { Confounding }\end{array}$ & Power & $\begin{array}{r}\text { Total } \\
\text { Score }\end{array}$ \\
\hline Larsen & 11 & 3 & 5 & 4 & 0 & 23 \\
Lee & 9 & 3 & 4 & 4 & 0 & 20 \\
Domínguez-Álvarez & 10 & 3 & 4 & 4 & 0 & 21 \\
McMahon & 9 & 3 & 4 & 4 & 0 & 20 \\
Tang & 9 & 3 & 5 & 4 & 0 & 21 \\
Takahashi & 9 & 3 & 5 & 4 & 0 & 21 \\
Moulin & 9 & 3 & 3 & 4 & 0 & 19 \\
Tso & 9 & 3 & 4 & 3 & 0 & 19 \\
Morgül & 5 & 2 & 3 & 2 & 0 & 12 \\
Cellini & 10 & 3 & 4 & 3 & 0 & 20 \\
\hline
\end{tabular}

Note.*Total Score and quality levels (Hooper et al., 2008): excellent (26-28); good (20-25); fair (15-19); and poor $(\leq 14)$.

2020). Across these studies, psychosocial factors were associated with elevated levels of emotional problems in children during mandatory school closures. Three studies reported on parental depression as a significant predictor increasing levels of emotional symptoms in children (Moulin et al., 2021; Takahashi \& Honda, 2021; Tso et al., 2020). Over a time period of five weeks of school closure, the likelihood of displaying emotional problems was particularly high when having a parent suffering from depression (Moulin et al., 2021). One study measuring the same association reported less likelihood of emotional difficulties in relation to the duration of prolonged school closures (Takahashi \& Honda, 2021). Mental disorders in mothers as primary caregivers showed moderate effects on children's emotional response $(B=0.40 ; p<0.001)$ (Tso et al., 2020). Furthermore, one study found that maternal difficulties in emotion regulation influenced emotional problems in schoolchildren indicating children absorbed higher levels of irritability from their mothers (Cellini et al., 2021). Ultimately, if children perceived higher levels of family stress and instability during school closure, they significantly reacted more emotional in the sense of sadness or angriness $(B=0.555, p<0.001)$ (Larsen et al., 2021). In one study children's emotional maladjustment was associated with low levels of parental dispositional resilience indicating a lack of stress resistance during quarantine $(B=-0.09, p<0.05)$ (Domínguez-Álvarez et al., 2020). The same study revealed an interaction between the contextual risk factor parental fear of future and child coping reflected in emotional symptoms. When children displayed disengagedoriented strategies to cope with the situation at home, higher levels of parental fear predicted higher levels of emotional symptoms in children $(B=0.14$, $p<0.03$ ). On the contrary, lower levels of parental dispositional resilience predicted higher levels of emotional problems if children displayed disengagement $(\beta=-0.07, p<0.002)$ However, the finding was age-dependent (Domínguez-Álvarez et al., 2020). Older children, age seven to 12 seemed to show more engaged oriented coping strategies in accordance to developmental trajectories such as problem solving, instrumental social support, or seeking understanding.

Children's conduct problems and associated psychosocial factors

Data of overall seven studies indicated the interplay of psychosocial factors and conduct problems as well as hyperactivity in children during the mandatory lockdown period (Cellini et al., 2021; DomínguezÁlvarez et al., 2020; Larsen et al., 2021; Morgül et al., 2020; Moulin et al., 2021; Takahashi \& Honda, 2021; Tso et al., 2020). Across four studies children in remote learning showed elevated levels of conduct problems and hyperactivity when exposed to parental depression (Moulin et al., 2021; Takahashi et al., 2021; Tso et al., 2020); mothers with mental disorders were especially associated with higher levels of conduct problems in children $(B=0.33, p<0.001)$ (Tso et al., 2020). As previously mentioned, if schools were closed for a prolonged period, children had to spend more time with depressed caregivers, which increased the likelihood of hyperactivity symptoms and conduct problems (Moulin et al., 2021). In contrast to this finding, Takahashi and Honda (2021) investigated the same association but reported a notable lower risk of increased hyperactive symptoms 
and behavioral problems in children when having a parent who suffered from depression. Another study reported on mothers who had difficulties in regulating their emotions appropriately, which potentially influenced behavioral problems and hyperactivity in their children, similar to the findings of emotional problems (Cellini et al., 2021). If caregivers showed signs of psychological distress, behavioral changes in children were more likely to be perceived by parents: e.g. children behaved uneasy or argued with family members more often (Morgül et al., 2020). Three studies found that parental stress or perceived family stress was associated with higher scores on behavior and hyperactivity scales (Domínguez-Álvarez et al., 2020; Larsen et al. 2021; Tso et al., 2020). Children reported on more somatic/cognitive reactions such as concentration issues or headaches when experiencing higher levels of stress and instability within the family setting $(B=0.356, p<0.001)$ (Larsen et al., 2021). One study found parental dispositional resilience negatively correlated with behavioral problems and hyperactivity (Domínguez-Álvarez et al., 2020). The less parents were able to cope with stressful situations the higher children scored in conduct problems $(B=-0.09, p<0.05)$ and hyperactivity $(B=-0.11$, $p<0.001)$. The same study reported on parental fear of future correlating positively with both dimensions and predicted higher levels of child behavioral problems when children displayed disengaged coping. Again, this result was dependent on age; older children were more engaged in coping. A final study reported on negative associations between parentchild interaction and children's behavioral problems, and hyperactivity levels (Tso et al., 2020). Children displayed higher levels of hyperactive symptoms if parents were less involved in recreational activities as well as learning activities with their children (Tso et al., 2020); both forms of parent-child interaction are considered important contributions to child development and child well-being.

\section{Comparison between longitudinal data and cross- sectional data}

On a clinically relevant level, longitudinal data revealed a notable rise of scores on SDQ scales as well as on PHQ-9 scales measuring parental depression if schools remained closed for an average of 69.7 days, in comparison to an earlier measure point with an average of 5.4 days of school closure (Takahashi \& Honda, 2021). In particular, the proportion of hyperactivity increased notably from $21.0 \%$ (mea- surement time 1) to $34.6 \%$ (measurement time 2) within a period of 10 weeks (Takahashi \& Honda, 2021). On the contrary, one cohort study collecting cross-sectional data on the interrelatedness of parents' mental health and children's psychological difficulties reported on a much higher likelihood of negative child outcomes if children were exposed to caregivers showing depressive symptoms compared to children without exposure to this risk factor (Moulin et al., 2021) versus longitudinal data analyzing the same interrelation reporting on much lower likelihood of negative child symptoms in a larger sample (Takahashi \& Honda, 2021). Regardless of whether longitudinal data or cross-sectional data, results on associations between psychosocial factors within the family environment and children's psychological difficulties resembled across study designs.

\section{Differences and similarities in findings across studies}

Larsen et al. (2021) and Tang et al. (2021) investigated children's view on their difficulties related to family characteristics during school closure. Albeit, items in child reports differed from parent reports in the complexity of wording and information. Findings regarding child perceived psychosocial factors impacting child reactions were similar to results generated by parent perspectives. Although compared to surveys completed by parents, children's emotional response to family stress was particularly strong according to their self-report $(\beta=0.555, p<0.001)$ (Larsen et al., 2021). One study comprising a relatively small sample, found no significant difference between depressed and non-depressed parents reporting on child anxiety scores, which implicated parental depression did not significantly determine children's anxiety level during mandatory lockdown (Lee et. al, 2021). Data across studies with larger samples seemed to reveal a different picture: higher levels of depression in parents significantly impacted negative outcomes in children (Cellini et al., 2021; McMahon et al, 2021; Morgül et al., 2020; Moulin et al., 2021; Takahashi \& Honda, 2021; Tso et al., 2020). In six studies children's emotional distress related to parental stressors was more pronounced compared to behavioral difficulties and levels of hyperactivity (Domínguez-Álvarez et al., 2020; Larsen et al., 2021; Morgül et al., 2020; Moulin et al., 2021; Takahashi \& Honda, 2021; Tso et al., 2020). Children reacted primarily emotional when exposed to parental depression (Morgül et al., 2020; Moulin et al., 2021; Takahashi \& Honda., 2021; Tso et al., 
2020) and parental stress (Domínguez-Álvarez et al., 2020; Larsen et al., 2021).

\section{Discussion}

This systematic review is aimed to synthesize the literature examining pandemic-related school closures and emerging psychosocial outcomes in children contingent on psychosocial risk factors within the environment of families. It was assumed that implemented school closures enhance psychosocial outcomes in children, which consequently exert negative impacts on children's mental health, as well as trajectories of psychosocial and emotional development. Findings support the interrelatedness of psychological difficulties in children and their primary caregivers as immediate socialization circle in the context of homeschooling. Across studies, children showed externalizing and internalizing symptoms referring to several common parentrelated variables. Psychosocial variables identified in this review included: parental stress, psychological distress in parents with anxiety and depression, parent-child interaction, and parenting stress.

Unsurprisingly, both children and parents reported changes in distress during the period of school closure; changes in child well-being were directly and indirectly influenced by situational and permanent psychological properties of caregivers. Children experienced elevated levels of anxiety, depressive symptoms, negative emotional response, behavioral problems, and hyperactivity. These results are consistent with previous studies reporting higher levels of anxiety and depression in children during lockdown (Liu et al., 2021; Xie et al., 2020), as well as noticeable changes in children's behavioral and emotional adjustment (Orgilés et al., 2020; Raviv et al., 2021; Tiwari et al., 2021). Parental mental health concerns and parental stress appeared to be associated with increased levels of emotional difficulties and hyperactive symptoms in children (DomínguezÁlvarez et al., 2020; Larsen et al., 2021; Moulin et al., 2021; Takahashi \& Honda, 2021; Tso et al., 2020), which in turn may reflect children's feeling of helplessness towards their unprecedented situation. Own negative emotional states, difficult behavior may be attempts of children to reduce negative effects of child perceived changes and inconsistencies in their caregiver's behavior, interpersonal exchanges, and elevated stress levels of parents (Langrock et al.,
2002) due to the pressure of lockdown and homeschooling.

With implemented school closures and other pandemic-related stressors, parents had to rapidly adapt to new daily routines, at-home education, fulltime caregiving, and accordingly disrupted working hours or even job loss. Data from previous research confirm higher stress rates of parents coping with the new setting of distance-learning (Martinsone \& Tzivian, 2021), and worsened parental mental health during quarantine (Furlong et al., 2021; Yamamura \& Tsustsui, 2021). Interestingly, McMahon et al. (2021) found negative impacts on children's mental health if parents were less able to support children's learning during COVID-19 restrictions, which was mediated by parental psychological distress. Foremostly in homeschooling, children required more academic and emotional support; relied on their parents as educators, which may have been overwhelming to already overburdened parents. Consequently, it is to speculate whether children felt rejected, which was reflected in the worsening of children's emotional and behavioral functioning.

Considering the role of mothers during school closures, results showed elevated levels of difficulties in children if mothers suffered from mental disorders (Cellini et al., 2021; Tso et al., 2020). The effect was less pronounced in the sample of Cellini et al. (2021). Compared to paternal psychopathology, a stronger association between higher rates of emotional reactions in children and poor maternal mental health was found (Tso et al., 2020). This finding may indicate children's primary attachment to their mothers due to the biological bond. Children are particularly vulnerable to maternal psychological impairments (Goodman et al., 2011). In most cases, mothers shouldered the marked change of family routines and caregiving, which opened a discussion on gender gaps (Cheng et al., 2021). During lockdown, children's vulnerabilities were aligned with mothers who showed difficulties in the regulation of emotions (Cellini et al., 2021). This observation was similar in an Italian sample with younger children (age 2 to 5) (Di Giorgio et al., 2021). It is possible that this review's finding demonstrates children's responsiveness to maternal irritability due to the reciprocal mother-child relationship (Kirby \& Hoàng, 2018). Then again, Zreik et al. (2021) argued that "mothers with poor emotional regulation tend to identify their children as more problematic and symptomatic" (Cellini et al., 2021, p. 162). Interestingly, during school closure, child anxiety was not significantly 
affected by parental depression (Lee et al., 2021). Psychopathologies in children emerge over time as confirmed by longitudinal data from a 10- yearfollow-up study (Nomura et al., 2002). In this study parental depression was proven as a strong risk factor for anxiety disorder in offspring (Nomura et al., 2002). Within the context of school closures, children were more likely to show impairments of emotional and behavioral functioning as a short-term reaction to parental depression (Morgül et al., 2020; Moulin et al., 2021; Takahashi \& Honda, 2021; Tso et al., 2020). As synthesized from the literature, longitudinal data unexpectedly revealed lower odds of the link between parental depression and child maladjustment (Takahashi \& Honda, 2021). In contrast, cross-sectional data of a French cohort study reported higher odds of the association between the exposure to a parent and child outcomes (Moulin et al., 2021). From a cultural point of view, it is possible that respond patterns differed in both cohorts. In Japan stigmatizing attitudes towards mental health disorders are more common than among Western countries (Griffiths et al., 2006). Bearing this in mind, parents of the Japanese cohort possibly feared the label "depression" and therefore withheld information on their (perceived) mental health status, affecting their children. On the other hand, higher odds ratios in the French cohort may have accounted for the conflictual environment of participants (Moulin et al., 2021).

With regard to parent-child interaction, results have demonstrated that the nature and a higher frequency of parent-child conversations about the disaster of COVID-19 were associated with less anxious and depressive symptoms in children (Tang et al., 2021). If children experienced quarantine negatively, they benefited from conversations with their parents resulting in fewer feelings of anxiety and depression (Tang et al., 2021). During adverse events such as the COVID-19 pandemic, involving widespread school closures, the separation from peers and educators, and the loss of learning activities, it is of utmost importance to discuss and explain the situation to children (Dalton et al., 2020). Children have more limited resources to understand the complexity of implemented restrictions and subsequent changes within their family environment; therefore, as a parent, it is crucial to ensure effective communication by providing honest information to a child (Stein et al., 2019). However, the finding by Tang et al. (2021) should be interpreted carefully. The aforementioned prevalence of children finding quarantine beneficial was relatively high compared to children disliking it. Furthermore, Chinese children growing up in a collectivist society may have responded in a more socially desirable manner according to the expected commitment towards the authority in parents (Lalwani et al., 2006). Results have shown that lacking recreational activities (e.g. physical activities and play), as well as lacking learning activities (e.g. scaffolded learning) during quarantine were associated with negative child outcomes (Tso et al., 2020). This finding is in line with studies reporting on sedentary lifestyles due to remote learning, which negatively impacted children's mental health (Dunton et al., 2020; Xiang et al., 2020). Viewed in the light of school closures, there may be barriers to encouraging play and activities due to lacking peer contact and lower motivation in parents to engage playfully with their children. Research has shown that appropriate play and learning activities with parents and peers are an opportunity to foster the social-emotional, cognitive, language, and self-regulation skills that build executive function and a "prosocial brain" (Bodrova et al., 2013; Cheng \& Mix, 2014; Hillman et al., 2014; Korczak et al., 2017; Lewis et al., 2000). The strain of distance-learning and isolation, less recreational time, less scaffolded learning through parents and educators may buffer the acquisition of social and emotional skills that are critical for academic success and positive engagement in life (Durlak et al., 2011).

The COVID-19 pandemic is an atypical scenario in which parental dispositional resilience and parental fear of future might be critical factors for child adjustment. Domínguez-Álvarez et al. (2020) found moderating effects of parental dispositional resilience and parental fear of future on the relation between child coping and psychological difficulties in children. For instance, when lower levels of parental dispositional resilience operated along with child disengagement strategies, negative child outcomes were observed; but in turn child engagement strategies produced positive child outcomes. This may seem a paradox; however, Domínguez-Álvarez et al. (2020) explained child coping strategies as compensatory actions to reduce toxic stress resulting in either positive or negative child outcomes when combined with parental factors. Coping strategies are primarily acquired through socialization processes. Literature shows that child coping responses are directly modeled by parent's own coping, which again highlights the role of parents as socialization agents (Kliewer et al., 1996) in times of COVID-19 and beyond. In the context of school closures, parental resources appear 
to be overwhelmed and parents may not be aware or capable of adequate coping suggestions, which might result in negative child outcomes. Given this fact, parents are challenged to make an effort to improve their resilience skills to better cope with stress under adverse circumstances such as the pandemic.

To sum it up, this review's findings relate to the results of the previous mentioned COPSY study (Ravens-Sieberer et al., 2021a; Ravens-Sieberer et al., 2021b): a worsening of children's mental health, as well as their psychosocial functioning was observed across studies. Ultimately, this emphasizes the risk children have to face when exposed to unfavorable family environments.

\section{Limitations of the Present Study}

Findings reported should be carefully interpreted. Associations between psychosocial factors and outcomes were identified but overall weak to moderate. However, it remains unclear to what extent measures of interest accounted for the explained variance in psychosocial health outcomes. Proportions of explained variance might allow a better view on the influence of potential risk factors, deriving from the family environment. Notwithstanding the influence of parent-related variables, existing literature reports on a variety of concurrent risk factors during school closure. For instance, children were as well subjected to social disparities, food insecurities, or increased media usage, to name a few (Dunn et al., 2020; Hawrilenko et al., 2021; Kim et al., 2021; Van Lancker \& Parolin, 2020). Taking other risk factors into account, negative psychosocial outcomes in schoolchildren are multifaceted and not entirely intertwined with parental characteristics. Another aspect considered as a limitation is the difficulty of the age range as well as different sample sizes across studies. Most studies comprised of small samples and included children at very different stages of development. Thus, it is difficult to determine the representativeness and generalizability of this review's findings. Future research should consider a clearer differentiation of age to address specific emotional and behavioral difficulties in children during school closure. Moreover, results of the studies might have been biased since the majority of participating caregivers were mothers. The role of fathers is just as important and should be considered in future investigations. Another limitation is the lack of valuable self-report by children since eight out of 10 studies focused on information provided by caregivers.
Furthermore, most findings on parent-child associations were derived from cross-sectional analyses, which are only informative on short-term effects and address a potential recall bias of information. Longitudinal methods might offer a more comprehensive view on the severity and direction of psychosocial outcomes in children. Finally, it cannot be ruled out that important studies - published or unpublished were missed in the wake of this search process.

\section{Conclusion}

In conclusion, this review provides an overview of specific family-related variables and psychosocial child outcomes during pandemic-related school closures. Furthermore, findings of this current review suggest that distance-learning showed an immediate impact on child well-being modeled by dyadic parent-child processes. Aside from risk factors, this review highlighted a few protective factors to help a child thrive under the atypical circumstance of pandemic-related school closures. How parents cope with the adverse situation of COVID-19 pandemic plays a crucial role in the social and emotional development of children, as well as children's mental health. However, the parent-child dynamic is a complex interaction between a child and their caregiving environment. In a previous study by Raviv et al. (2021), findings underpinned the parent-child dynamic as a transactional process: children's behavioral maladjustment during lockdown influenced parenting stress, which in turn affected parents' "ability to regulate their own emotions" and thus "manage their children's behavior" (Raviv et al., 2021, p. 7). This transactional mechanism may exacerbate children's behavioral, as well as emotional difficulties and increase the risk for child maltreatment. Findings suggest that additional support should be targeted at children in vulnerable families to reduce the deepening of emotional, social, and psychological harm during school closures. From a developmental perspective, one should bear in mind that parenting cannot entirely satisfy socialization processes in a child's life. In other words, school serves as another major agent of socialization, implementing essential learning and building relationships outside the family environment. In developmental stages of heightened sensitivity, the context of school helps children to build wholesome attitudes towards the self, to achieve personal identity, and gain independence from parents. In times of pandemic-related school closures, 
children may be deprived of these opportunities, which in conclusion highlights the unique role of the concept "school". Globally, policymakers have come to terms that education is responsible for the economic and social progress of society. The thread of society's development relies on well-balanced children and families.

\section{Acknowledgments}

We would like to thank the following fellow student for her assistance in searching the literature and determining rater agreement: Laurien Pausewein.

\section{References}

Araújo, L. A., Veloso, C. F., Souza, M. C., Azevedo, J. M. C., \& Tarro, G. (2021). The potential impact of the COVID-19 pandemic on child growth and development: A systematic review. Jornal de Pediatria, 97(4), 369-377. https://doi.org/10.1016/j.jped.2020.08.008

Berger, E., Jamshidi, N., Reupert, A., Jobson, L., \& Miko, A. (2021). Review: The mental health implications for children and adolescents impacted by infectious outbreaks a systematic review. Child and Adolescent Mental Health, 26(2), 157-166. https://doi.org/https://doi.org/10.1111/camh. 12453

Bodrova, E., Germeroth, C., \& Leong, D. (2013). Play and selfregulation: Lessons from Vygotsky. American Journal of Play, 6, 111-123.

Bowler, G., \& Weinraub, M. (2018). Developmental tasks. In M. H. Bornstein (Ed.), The SAGE encyclopedia of lifespan human development (pp. 597-598). SAGE.

Bradley, R. H., \& Corwyn, R. F. (2002). Socioeconomic status and child development. Annual Review of Psychology, 53(1), 371-399. https://doi.org/10.1146/annurev. psych.53.100901.135233

Brandal, L. T., Ofitserova, T. S., Meijerink, H., Rykkvin, R., Lund, H. M., Hungnes, O., Greve-Isdahl, M., Bragstad, K., Nygård, K., \& Winje, B. A. (2021). Minimal transmission of SARSCoV-2 from paediatric COVID-19 cases in primary schools, Norway, August to November 2020. Eurosurveillance, 26(1), 2002011. https://doi.org/doi:https://doi.org/10.2807/15607917.ES.2020.26.1.2002011

Calvano, C., Engelke, L., Di Bella, J., Kindermann, J., Renneberg, B., \& Winter, S. M. (2021). Families in the COVID-19 pandemic: parental stress, parent mental health and the occurrence of adverse childhood experiences-results of a representative survey in Germany. European Child and Adolescent Psychiatry, 1-13. https://doi.org/10.1007/s00787-02101739-0

Cavallo, F., Rossi, N., \& Chiarelli, F. (2020). Novel coronavirus infection and children. Acta Biomedica, 91(2), 172-176. https://doi.org/10.23750/abm.v91i2.9586

Cellini, N., Di Giorgio, E., Mioni, G., \& Di Riso, D. (2021). Sleep and psychological difficulties in Italian school-age children during COVID-19 lockdown. Journal of Pediatric Psychology, 46(2), 153-167. https://doi.org/10.1093/jpepsy/jsab003

Cheng, Y.-L., \& Mix, K. S. (2014). Spatial training improves children's mathematics ability. Journal of Cognition and Development, 15(1), 2-11. https://doi.org/10.1080/15248372. 2012.725186

Cheng, Z., Mendolia, S., Paloyo, A. R., Savage, D. A., \& Tani, M. (2021). Working parents, financial insecurity, and childcare: mental health in the time of COVID-19 in the UK. Review of Economics of the Household, 19, 123-144. https://doi.org/10.1007/s11150-020-09538-3

Collins, C., Landivar, L. C., Ruppanner, L., \& Scarborough, W. J. (2021). COVID-19 and the gender gap in work hours. Gender, Work \& Organization, 28(S1), 101-112. https://doi.org/ https://doi.org/10.1111/gwao.12506

Dalton, L., Rapa, E., \& Stein, A. (2020). Protecting the psychological health of children through effective communication about COVID-19. The Lancet - Child and Adolescent Health, 4(5), 346-347. https://doi.org/10.1016/s2352-4642(20)30097-3

Di Giorgio, E., Di Riso, D., Mioni, G., \& Cellini, N. (2021). The interplay between mothers' and children behavioral and psychological factors during COVID-19: An Italian study. European Child \& Adolescent Psychiatry, 30(9), 1401-1412. https://doi.org/10.1007/s00787-020-01631-3

Domínguez-Álvarez, B., López-Romero, L., Isdahl-Troye, A., Gómez-Fraguela, J. A., \& Romero, E. (2020). Children coping, contextual risk and their interplay during the COVID-19 pandemic: A Spanish case. Frontiers in Psychology, 11(3427). https://doi.org/10.3389/fpsyg.2020.577763

Downs, S. H., \& Black, N. (1998). The feasibility of creating a checklist for the assessment of the methodological quality both of randomised and non-randomised studies of health care interventions. Journal of Epidemiology and Community Health, 52(6), 377-384. https://doi.org/10.1136/jech.52.6.377

Dunn, C. G., Kenney, E., Fleischhacker, S. E., \& Bleich, S. N. (2020). Feeding low-income children during the Covid-19 pandemic. New England Journal of Medicine, 382(18), e40. https://doi.org/10.1056/NEJMp2005638

Dunton, G. F., Do, B., \& Wang, S. D. (2020). Early effects of the COVID-19 pandemic on physical activity and sedentary behavior in children living in the U.S. Bmc Public Health, 20(1), 1351. https://doi.org/10.1186/s12889-020-09429-3

Durlak, J. A., Weissberg, R. P., Dymnicki, A. B., Taylor, R. D., \& Schellinger, K. B. (2011). The impact of enhancing students' social and emotional learning: A meta-analysis of school-based universal interventions. Child Development, 82(1), 405-432. https://doi.org/10.1111/j.1467-8624.2010.01564.x

van Eldik, W. M., de Haan, A. D., Parry, L. Q., Davies, P. T., Luijk, M., Arends, L. R., \& Prinzie, P. (2020). The interparental relationship: Meta-analytic associations with children's maladjustment and responses to interparental conflict. Psychological Bulletin, 146(7), 553-594. https://doi.org/10.1037/bu1000 0233

Furlong, M., McGilloway, S., Mulligan, C., Killion, M. G., McGarr, S., Grant, A., Davidson, G., \& Donaghy, M. (2021). Covid-19 and families with parental mental illness: Crisis and opportunity. Frontiers in Psychiatry, 12(1263), 1-9, Article 567447. https://doi.org/10.3389/fpsyt.2021.567447

Gadermann, A. C., Thomson, K. C., Richardson, C. G., Gagné, M., McAuliffe, C., Hirani, S., \& Jenkins, E. (2021). Examining the impacts of the COVID-19 pandemic on family mental health in Canada: Findings from a national cross-sectional study. Bmj 
Open, 11(1), e042871. https://doi.org/10.1136/bmjopen-2020042871

Gassman-Pines, A., Ananat, E. O., \& Fitz-Henley, J., 2nd. (2020). COVID-19 and parent-child psychological wellbeing. Pediatrics, 146(4), e2020007294. https://doi.org/10. 1542/peds.2020-007294

Goodman, S. H., Rouse, M. H., Connell, A. M., Broth, M. R., Hall, C. M., \& Heyward, D. (2011). Maternal depression and child psychopathology: A meta-analytic review. Clinical Child and Family Psychology Review, 14(1), 1-27. https://doi.org/10.1007/s10567-010-0080-1

Griffiths, K. M., Nakane, Y., Christensen, H., Yoshioka, K., Jorm, A. F., \& Nakane, H. (2006). Stigma in response to mental disorders: a comparison of Australia and Japan. BMC Psychiatry, 6(1), 21. https://doi.org/10.1186/1471-244X-6-21

Hammen, C., Burge, D., Burney, E., \& Adrian, C. (1990). Longitudinal study of diagnoses in children of women with unipolar and bipolar affective disorder. Archives of General Psychiatry, 47(12), 1112-1117. https://doi.org/10.1001/archpsyc. 1990.01810240032006

Havighurst, R. J. (1956). Research on the developmental-task concept. The School Review, 64(5), 215-223. https://doi.org/ $10.1086 / 442319$

Hawrilenko, M., Kroshus, E., Tandon, P., \& Christakis, D. (2021). The association between school closures and child mental health during COVID-19. Jama Network Open, 4(9), e2124092-e2124092. https://doi.org/10.1001/jamanetwork open.2021.24092

Hillman, C. H., Pontifex, M. B., Castelli, D. M., Khan, N. A., Raine, L. B., Scudder, M. R., Drollette, E. S., Moore, R. D., Wu, C.-T., \& Kamijo, K. (2014). Effects of the FITKids randomized controlled trial on executive control and brain function. Pediatrics, 134(4), e1063-e1071. https://doi.org/10.1542/peds.2013-3219

Holt, S., Buckley, H., \& Whelan, S. (2008). The impact of exposure to domestic violence on children and young people: A review of the literature. Child Abuse and Neglect, 32(8), 797-810. https://doi.org/10.1016/j.chiabu.2008.02.004

Hooper, P., Jutai, J. W., Strong, G., \& Russell-Minda, E. (2008). Age-related macular degeneration and low-vision rehabilitation: a systematic review. Canadian Journal of Ophthalmology, 43(2), 180-187. https://doi.org/10.3129/i08-001

Huebener, M., Waights, S., Spiess, C. K., Siegel, N. A., \& Wagner, G. G. (2021). Parental well-being in times of Covid-19 in Germany. Review of Economics of the Household, 19(1), 91-122. https://doi.org/10.1007/s11150-020-09529-4

Ihle, W., \& Esser, G. (2002). Epidemiologie psychischer Störungen im Kindes- und Jugendalter: Prävalenz, Verlauf, Komorbidität und Geschlechtsunterschiede. Psychologische Rundschau, 53, 159-169. https://doi.org/10.1026/0033-3042.53.4.159

Ismail, S. A., Saliba, V., Lopez Bernal, J., Ramsay, M. E., \& Ladhani, S. N. (2021). SARS-CoV-2 infection and transmission in educational settings: A prospective, crosssectional analysis of infection clusters and outbreaks in England. The Lancet - Infectious Disease, 21(3), 344-353. https://doi.org/10.1016/s1473-3099(20)30882-3

Jackson, C., Vynnycky, E., \& Mangtani, P. (2016). The relationship between school holidays and transmission of influenza in England and Wales. American J Epidemiology, 184(9), 644-651. https://doi.org/10.1093/aje/kww083

Jiao, W. Y., Wang, L. N., Liu, J., Fang, S. F., Jiao, F. Y., Pettoello-Mantovani, M., \& Somekh, E. (2020). Behavioral and emotional disorders in children during the COVID-19 epidemic. Journal of Pediatrics, 221, 264-266.e261. https:// doi.org/10.1016/j.jpeds.2020.03.013

Kim, S. J., Lee, S., Han, H., Jung, J., Yang, S. J., \& Shin, Y. (2021). Parental mental health and children's behaviors and media usage during COVID-19-related school closures. Journal of the Korean Academy of Medical Sciences, 36(25), e184. https://doi.org/10.3346/jkms.2021.36.e184

Kirby, J. N., \& Hoàng, N. (2018). Parenting of adult children: A neglected area of parenting studies. In M.R. Sanders \& A. Morawska (Eds.), Handbook of parenting and child development across the lifespan (pp. 653-675). Springer. https://doi.org/10.1007/978-3-319-94598-9_29

Kliewer, W., Fearnow, M. D., \& Miller, P. A. (1996). Coping socialization in middle childhood: Tests of maternal and paternal influences. Child Development, 67(5), 2339-2357. https://doi.org/10.2307/1131627

Korczak, D. J., Madigan, S., \& Colasanto, M. (2017). Children's physical activity and depression: a meta-analysis. Pediatrics, 139(4). https://doi.org/10.1542/peds.2016-2266

Lalwani, A. K., Shavitt, S., \& Johnson, T. (2006). What is the relation between cultural orientation and socially desirable responding? Journal of Personality and Social Psychology, 90(1), 165-178. https://doi.org/10.1037/0022-3514.90.1.165

Langrock, A. M., Compas, B. E., Keller, G., Merchant, M. J., \& Copeland, M. E. (2002). Coping with the stress of parental depression: Parents' reports of children's coping, emotional, and behavioral problems. Journal of Clinical Child and Adolescent Psychology, 31(3), 312-324. https://doi.org/10.1207/s15374424jccp3103_03

Larsen, L., Helland, M. S., \& Holt, T. (2021). The impact of school closure and social isolation on children in vulnerable families during COVID-19: A focus on children's reactions. European Child and Adolescent Psychiatry, 1-11. https://doi.org/10.1007/s00787-021-01758-x

Lee, J. (2020). Mental health effects of school closures during COVID-19. The Lancet - Child and Adolescent Health, 4(6), 421. https://doi.org/10.1016/s2352-4642(20)30109-7

Lee, S. J., Ward, K. P., Chang, O. D., \& Downing, K. M. (2021). Parenting activities and the transition to home-based education during the COVID-19 pandemic. Children and Youth Services Review, 122, 105585. https://doi.org/10.1016/ j.childyouth.2020.105585

Lewis, S. J., Munro, A. P. S., Smith, G. D., \& Pollock, A. M. (2021). Closing schools is not evidence based and harms children. British Medical Journal, 372, n521. https://doi.org/10.1136/bmj.n521

Lewis, V., Boucher, J., Lupton, L., \& Watson, S. (2000). Relationships between symbolic play, functional play, verbal and non-verbal ability in young children. International Journal of Language and Communication Disorders, 35(1), 117-127. https://doi.org/10.1080/136828200247287

Liu, Y., Yue, S., Hu, X., Zhu, J., Wu, Z., Wang, J., \& Wu, Y. (2021). Associations between feelings/behaviors during COVID-19 pandemic lockdown and depression/anxiety after lockdown in a sample of Chinese children and adolescents. Journal of Affective Disorders, 284, 98-103. https://doi.org/10. 1016/j.jad.2021.02.001

Loades, M. E., Chatburn, E., Higson-Sweeney, N., Reynolds, S., Shafran, R., Brigden, A., Linney, C., McManus, M. N., Borwick, C., \& Crawley, E. (2020). Rapid systematic review: The impact of social isolation and loneliness on the mental health of children and adolescents in the context of COVID-19. 
Journal of the American Academy of Child and Adolescent Psychiatry, 59(11), 1218-1239.e1213. https://doi.org/ 10.1016/j.jaac.2020.05.009

Ludvigsson, J. F. (2020). Systematic review of COVID-19 in children shows milder cases and a better prognosis than adults. Acta Paediatrica, 109(6), 1088-1095. https://doi.org/10.1111/apa.15270

Macartney, K., Quinn, H. E., Pillsbury, A. J., Koirala, A., Deng, L., Winkler, N., Katelaris, A. L., O'Sullivan, M. V. N., Dalton, C., \& Wood, N. (2020). Transmission of SARS-CoV-2 in Australian educational settings: A prospective cohort study. The Lancet - Child and Adolescent Health, 4(11), 807-816. https://doi.org/10.1016/s2352-4642(20)30251-0

Martinsone, B., \& Tzivian, L. (2021). Differences in stress and coping during the COVID-19 pandemic in families with and without children with developmental disorders or chronic conditions. Frontiers in Public Health, 9(1170). https://doi.org/10.3389/fpubh.2021.704577

Masten, A. S., \& Coatsworth, J. D. (1995). Competence, resilience, and psychopathology: Risk, disorder, and adaptation. In D. Cicchetti \& D. Cohen (Eds.), Developmental psychopathology Vol. 2: Risk, disorder, and adaptation (pp. 715-752). Wiley.

Masten, A. S., Roisman, G. I., Long, J. D., Burt, K. B., Obradović, J., Riley, J. R., Boelcke-Stennes, K., \& Tellegen, A. (2005). Developmental cascades: Linking academic achievement and externalizing and internalizing symptoms over 20 years. Developmental Psychology, 41(5), 733-746. https://doi.org/10.1037/0012-1649.41.5.733

McKune, S. L., Acosta, D., Diaz, N., Brittain, K., Beaulieu, D. J., Maurelli, A. T., \& Nelson, E. J. (2021). Psychosocial health of school-aged children during the initial COVID-19 safer-athome school mandates in Florida: A cross-sectional study. Bmc Public Health, 21(1), 603. https://doi.org/10.1186/s12889021-10540-2

McLeod, J. D., \& Kaiser, K. (2004). Childhood emotional and behavioral problems and educational attainment. American Sociological Review, 69(5), 636-658. https://doi.org/10.1177/ 000312240406900502

McMahon, J., Gallagher, E. A., Walsh, E. H., \& O'Connor, C. (2021). Experiences of remote education during COVID19 and its relationship to the mental health of primary school children. Irish Educational Studies, 40(2), 457-468. https://doi.org/10.1080/03323315.2021.1932555

Miller-Lewis, L. R., Sawyer, A. C. P., Searle, A. K., Mittinty, M. N., Sawyer, M. G., \& Lynch, J. W. (2014). Student-teacher relationship trajectories and mental health problems in young children. Bmc Psychology, 2(1), 27. https://doi.org/10.1186/s40359-014-0027-2

Monnier, M., Moulin, F., Thierry, X., Vandentorren, S., Côté, S., Barbosa, S., Falissard, B., Charles, M.-A., Simeon, T., Geay, B., Marchand, L., Ancel, P.-Y., Melchior, M., Rouquette, A., Galera, C., \& Plancoulaine, S. (2021). Children's mental and behavioral health, schooling, sociodemographic and socioeconomic characteristics during school closure in France due to COVID-19: The SAPRIS Project. In: Research Square. (Reprinted from: PREPRINT (Version 1)).

Morgül, E., Kallitsoglou, A., \& Essau, C. A. (2020). Psychological effects of the COVID-19 lockdown on children and families in the UK. Revista De Psicologia Clinica Con Ninos Y Adolescentes, 7(3), 42-48. https://doi.org/10.21134/ rpcna.2020.mon.2049
Mossong, J., Mombaerts, L., Veiber, L., Pastore, J., Coroller, G. L., Schnell, M., Masi, S., Huiart, L., \& Wilmes, P. (2021). SARSCoV-2 transmission in educational settings during an early summer epidemic wave in Luxembourg, 2020. BMC Infectious Diseases, 21(1), 417. https://doi.org/10.1186/s12879-02106089-5

Moulin, F., El-Aarbaoui, T., Bustamante, J. J. H., Héron, M., MaryKrause, M., Rouquette, A., Galéra, C., \& Melchior, M. (2021). Risk and protective factors related to children's symptoms of emotional difficulties and hyperactivity/inattention during the COVID-19-related lockdown in France: results from a community sample. European Child \& Adolescent Psychiatry, 1-12. https://doi.org/10.1007/s00787-021-01752-3

Nomura, Y., Wickramaratne, P. J., Warner, V., Mufson, L., \& Weissman, M. M. (2002). Family discord, parental depression, and psychopathology in offspring: Ten-year follow-up. Journal of the American Academy of Child and Adolescent Psychiatry, 41(4), 402-409. https://doi.org/10.1097/00004583200204000-00012

Orgilés, M., Morales, A., Delvecchio, E., Mazzeschi, C., \& Espada, J. P. (2020). Immediate psychological effects of the COVID-19 quarantine in youth from Italy and Spain. Frontiers in Psychology, 11, 579038. https://doi.org/10.3389/fpsyg.2020.579038

Ormel, J., Oldehinkel, A. J., Sijtsema, J., van Oort, F., Raven, D., Veenstra, R., Vollebergh, W. A., \& Verhulst, F. C. (2012). The TRacking Adolescents' Individual Lives Survey (TRAILS): Design, current status, and selected findings. Journal of the American Academy of Child and Adolescent Psychiatry, 51(10), 1020-1036. https://doi.org/10.1016/j.jaac.2012.08.004

Otto, C., Reiss, F., Voss, C., Wüstner, A., Meyrose, A. K., Hölling, H., \& Ravens-Sieberer, U. (2020). Mental health and well-being from childhood to adulthood: Design, methods and results of the 11-year follow-up of the BELLA study. European Child and Adolescent Psychiatry, 1-19. https://doi.org/10.1007/s00787-020-01630-4

Packer, J., Croker, H., Russell, S., Hope, S., Viner, R., Bonell, C., Ward, J., Hudson, L., Mytton, O., Stansfield, C., Thomas, J., Minozzi, S., Saulle, R., Schwalbe, N., \& Morgan, A. (2020). Short and long term impacts of school closures, or other isolation measures in childhood, on physical and mental health (CRD42020181658) [Systematic review]. Prospero. https://www.crd.york.ac.uk/prospero/display_record.php?ID= CRD42020181658

Page, M. J., McKenzie, J. E., Bossuyt, P. M., Boutron, I., Hoffmann, T. C., Mulrow, C. D., Shamseer, L., Tetzlaff, J. M., Akl, E. A., Brennan, S. E., Chou, R., Glanville, J., Grimshaw, J. M., Hróbjartsson, A., Lalu, M. M., Li, T., Loder, E. W., MayoWilson, E., McDonald, S., McGuinness, L. A., Stewart, L. A., Thomas, J., Tricco, A. C., Welch, V. A., Whiting, P., \& Moher, D. (2021). The PRISMA 2020 statement: An updated guideline for reporting systematic reviews. British Medical Journal, 372, n71. https://doi.org/10.1136/bmj.n71

Plass, A., Haller, A.-C., Habermann, K., Barkmann, C., Petermann, F., Schipper, M., Wiegand-Grefe, S., Hölling, H., Ravens-Sieberer, U., \& Klasen, F. (2016). Faktoren der Gesunderhaltung bei Kindern psychisch belasteter Eltern. Ergebnisse der BELLA-Kohortenstudie. [Factors promoting mental health in children of parents with mental health problems: Results of the BELLA cohort study.]. Kindheit und Entwicklung, 25(1), 41-49. https://doi.org/10.1026/0942-5403/a000187

Posserud, M.-B., \& Lundervold, A. J. (2013). Mental health services use predicted by number of mental health problems and 
gender in a total population study. The Scientific World Journal, 2013, 247283. https://doi.org/10.1155/2013/247283

Raitasalo, K., Holmila, M., Jääskeläinen, M., \& Santalahti, P. (2019). The effect of the severity of parental alcohol abuse on mental and behavioural disorders in children. European Child and Adolescent Psychiatry, 28(7), 913-922. https://doi.org/10.1007/s00787-018-1253-6

Ravens-Sieberer, U., Kaman, A., Erhart, M., Devine, J., Hölling, H., Schlack, R., Löffler, C., Hurrelmann, K., \& Otto, C. (2021a). Quality of life and mental health in children and adolescents during the first year of the COVID-19 pandemic in Germany: Results of a two-wave nationally representative study. (March 5, 2021). Available at SSRN: https://ssrn.com/ abstract $=3798710$ or http://dx.doi.org/10.2139/ssrn. 3798710

Ravens-Sieberer, U., Kaman, A., Erhart, M., Devine, J., Schlack, R., \& Otto, C. (2021b). Impact of the COVID-19 pandemic on quality of life and mental health in children and adolescents in Germany. European Child and Adolescent Psychiatry, 1-11. https://doi.org/10.1007/s00787-021-01726-5

Ravens-Sieberer, U., \& Kurth, B. M. (2008). The mental health module (BELLA study) within the German Health Interview and Examination Survey of Children and Adolescents (KiGGS): Study design and methods. European Child and Adolescent Psychiatry, 17(Suppl 1), 10-21. https://doi.org/10.1007/s00787-008-1002-3

Ravens-Sieberer, U., Otto, C., Kriston, L., Rothenberger, A., Döpfner, M., Herpertz-Dahlmann, B., Barkmann, C., Schön, G., Hölling, H., Schulte-Markwort, M., \& Klasen, F. (2015). The longitudinal BELLA study: Design, methods and first results on the course of mental health problems. European Child and Adolescent Psychiatry, 24(6), 651-663. https://doi.org/10.1007/s00787-014-0638-4

Raviv, T., Warren, C. M., Washburn, J. J., Kanaley, M. K., Eihentale, L., Goldenthal, H. J., Russo, J., Martin, C. P., Lombard, L. S., Tully, J., Fox, K., \& Gupta, R. (2021). Caregiver perceptions of children's psychological well-being during the COVID-19 pandemic. Jama Network Open, 4(4), e2111103e2111103. https://doi.org/10.1001/jamanetworkopen.2021. 11103

Rollings, K. A., Wells, N., Evans, G., Bednarz, A., \& Yang, Y. (2017). Housing and neighborhood physical quality: Children's mental health and motivation. Journal of Environmental Psychology, 50, 17-23.

Rutter, M., \& Quinton, D. (1984). Parental psychiatric disorder: effects on children. Psychological Medicine, 14(4), 853-880. https://doi.org/10.1017/s0033291700019838

Southwick, S. M., Vythilingam, M., \& Charney, D. S. (2005). The psychobiology of depression and resilience to stress: implications for prevention and treatment. Annual Review of Clinical Psychology, 1, 255-291. https://doi.org/10.1146/annurev.clinpsy.1.102803.143948

Stein, A., Dalton, L., Rapa, E., Bluebond-Langner, M., Hanington, L., Stein, K. F., Ziebland, S., Rochat, T., Harrop, E., Kelly, B., \& Bland, R. (2019). Communication with children and adolescents about the diagnosis of their own life-threatening condition. Lancet, 393(10176), 1150-1163. https://doi.org/10.1016/s0140-6736(18)33201-x

Takahashi, F., \& Honda, H. (2021). Prevalence of clinicallevel emotional/behavioral problems in schoolchildren during the coronavirus disease 2019 pandemic in Japan: A prospective cohort study. JCPP Advances, 1(1), e12007. https://doi.org/https://doi.org/10.1111/jcv2.12007
Tang, S., Xiang, M., Cheung, T., \& Xiang, Y. T. (2021). Mental health and its correlates among children and adolescents during COVID-19 school closure: The importance of parentchild discussion. Journal of Affective Disorders, 279, 353-360. https://doi.org/10.1016/j.jad.2020.10.016

Thomson, K. C., Richardson, C. G., Gadermann, A. M., Emerson, S. D., Shoveller, J., \& Guhn, M. (2019) Association of childhood social-emotional functioning profiles at school entry with early-onset Mental health conditions. Jama Network Open, 2(1), e186694-e186694. https://doi.org/10.1001/jamanetworkopen.2018.6694

Tiwari, G. K., Singh, A. K., Parihar, P., Pandey, R., Sharma, D. N., \& Rai, P. K. (2021). Understanding the perceived psychological distress and health outcomes of children during COVID-19 pandemic. The Educational and Developmental Psychologist, 1-12. https://doi.org/10.1080/20590776.2021.1899749

Tso, W. W. Y., Wong, R. S., Tung, K. T. S., Rao, N., Fu, K. W., Yam, J. C. S., Chua, G. T., Chen, E. Y. H., Lee, T. M. C., Chan, S. K. W., Wong, W. H. S., Xiong, X., Chui, C. S., Li, X., Wong, K., Leung, C., Tsang, S. K. M., Chan, G. C. F., Tam, P. K. H., Chan, K. L., Kwan, M. Y. W., Ho, M. H. K., Chow, C. B., Wong, I. C. K., \& Lp, P. (2020). Vulnerability and resilience in children during the COVID-19 pandemic. European Child and Adolescent Psychiatry, 17, 1-16. https://doi.org/10.1007/ s00787-020-01680-8

UNESCO. (2020). COVID-19 educational disruption and response. Retrieved July 19, 2021 from https://en.unesco.org/ news/covid-19-educational-disruption-and-response

UNICEF. (2021). COVID-19 and School Closures. One Year of Education Disruption. Retrieved May 5, 2021 from https:// data.unicef.org/resources/one-year-of-covid-19-and-schoolclosures/

Van Lancker, W., \& Parolin, Z. (2020). COVID-19, school closures, and child poverty: a social crisis in the making. The Lancet Public Health, 5(5), e243-e244. https://doi.org/10. 1016/S2468-2667(20)30084-0

Viner, R. M., Russell, S. J., Croker, H., Packer, J., Ward, J., Stansfield, C., Mytton, O., Bonell, C., \& Booy, R. (2020). School closure and management practices during coronavirus outbreaks including COVID-19: a rapid systematic review. The Lancet - Child and Adolescent Health, 4(5), 397-404. https://doi.org/10.1016/s2352-4642(20)30095-x

Wickens, C. M., Hamilton, H. A., Elton-Marshall, T., Nigatu, Y. T., Jankowicz, D., \& Wells, S. (2021). Household- and employment-related risk factors for depressive symptoms during the COVID-19 pandemic. Canadian Journal of Public Health, 112(3), 391-399. https://doi.org/10.17269/s41997020-00472-6

Wille, N., Bettge, S., \& Ravens-Sieberer, U. (2008). Risk and protective factors for children's and adolescents' mental health: results of the BELLA study. European Child and Adolescent Psychiatry, 17(Suppl 1), 133-147. https://doi. org/10.1007/s00787-008-1015-y

Xiang, M., Zhang, Z., \& Kuwahara, K. (2020). Impact of COVID19 pandemic on children and adolescents' lifestyle behavior larger than expected. Progress in Cardiovascular Diseases, 63(4), 531-532. https://doi.org/10.1016/j.pcad.2020.04.013

Xie, X., Xue, Q., Zhou, Y., Zhu, K., Liu, Q., Zhang, J., \& Song, R. (2020). Mental health status among children in home confinement during the coronavirus disease 2019 outbreak in Hubei Province, China. JAMA Pediatrics, 174(9), 898-900. https://doi.org/10.1001/jamapediatrics.2020.1619 
Yamamura, E., \& Tsustsui, Y. (2021). School closures and mental health during the COVID-19 pandemic in Japan. Journal of Population Economics, 34(4), 1261-1298. https://doi.org/10.1007/s00148-021-00844-3

Zhang, A., Liu, J., Yuan, K., Bao, Y., \& Lu, L. (2020). Mental health consequences of children and adolescents exposed to pandemics: A meta-analysis and systematic review (CRD42020221223) [Systematic review]. Prospero. https:// www.crd.york.ac.uk/prospero/display_record.php?ID=CRD4 2020221223

Zreik, G., Asraf, K., Haimov, I., \& Tikotzky, L. (2021). Maternal perceptions of sleep problems among children and mothers during the coronavirus disease 2019 (COVID-19) pandemic in Israel. Journal of Sleep Research, 30(1), e13201. https://doi.org/10.1111/jsr.13201

\section{Bio Sketches}

Juliane Lehmann graduated in the Bachelor Program in Clinical Psychology and Psychotherapy at Freie Universität Berlin.
Viola Lechner is Research Assistant in the Department of Education and Psychology - Unit "Developmental Science and Applied Developmental Psychology" at Freie Universität Berlin, Germany. Her research interests are the development and evaluation of preventive interventions, social-emotional learning, positive psychology and bullying prevention.

Herbert Scheithauer is Professor of Developmental and Clinical Psychology at Freie Universität Berlin, Germany, and Head of the Unit "Developmental Science and Applied Developmental Psychology". His research interests are bullying, cyberbullying, and the development and evaluation of preventive interventions. 